\title{
Numerical Weather Prediction Model Performance over High Southern Latitudes
}

\author{
Stephen F. Pendlebury \\ Regional Forecasting Centre, Bureau of Meteorology, Hobart, Australia \\ NeIL D. AdAms \\ Antarctic Co-operative Research Centre and Bureau of Meteorology, Hobart, Australia \\ TERRY L. HART \\ National Meteorological and Oceanographic Centre, Bureau of Meteorology, Melbourne, Australia \\ JOHN TURNER \\ Physical Sciences Division, British Antarctic Survey, Cambridge, United Kingdom
}

(Manuscript received 20 March 2001, in final form 14 September 2001)

\begin{abstract}
Increasingly, output from numerical weather prediction (NWP) models is being used for real-time weather forecasts for the Antarctic and for Antarctic-related climate diagnostics studies. Evidence is presented that indicates that in broad terms, the NWP output from the major global models is providing useful representations of synoptic-scale systems over high southern latitude areas. For example, root-mean-square (rms) errors in the European Centre for Medium-Range Weather Forecasts (ECMWF) model predictions of the 500-hPa height field indicate a day's gain in predictability since the mid-1990s: average rms errors in ECMWF $+72 \mathrm{~h} 500$-hPa height field prognoses for the calendar year 2000 were close to $50 \mathrm{~m}$, compared to similar errors in the $+48 \mathrm{~h}$ prognoses in 1995. Similar relative improvements may be noted for all time steps out to $+144 \mathrm{~h}$. Moreover, it is determined that, of the models considered here, the ECMWF model is clearly the most successful model at 500-hPa-height prediction for high southern latitudes, with the United Kingdom Met Office (UKMO) and National Centers for Environmental Prediction Aviation (AVN) models the next most accurate, and with the Australian Bureau of Meteorology's Global Assimilation Prediction (GASP) and Japanese Meteorological Agency (JMA) models lagging in accuracy. However, improvements in the temporal and spatial resolution of observational data that are available to the analysis and assimilation cycles of the NWP models, and improvements in the horizontal resolutions of the models, are required before the use of NWP output at high southern latitudes is as effective as in more northern areas of the world. Limited area modeling is seen as having potential for complementing the global models by resolving the finer-scale orography and topography of the Antarctic.
\end{abstract}

\section{Introduction}

For high southern latitudes, and in the Antarctic context in particular, users have to be aware that the output from the numerical weather prediction (NWP) systems cannot yet be used with the same confidence as in midlatitudes, where there is a huge number of verification statistics on model analysis and prognosis performance (see, e.g., Bengtsson 1991). Analysis validation and prognosis verification data for the Antarctic are relatively limited, although slowly increasing in number. The evidence in the literature is also somewhat variable in conclusions as to the worth of NWP in the Antarctic.

Corresponding author address: Stephen F. Pendlebury, Bureau of Meteorology, GPO Box 727, Hobart 7001, Australia.

E-mail: s.pendlebury@bom.gov.au
For example, the First Regional Observing Study of the Troposphere (FROST) over the Antarctic (Turner et al. 1996; Hutchinson et al. 1999), which examined the quality of Antarctic analyses, found that the models were fairly good over the ocean areas, but lacked mesoscale and small synoptic-scale details that are often of concern to the forecaster.

Adams (1997) also has reservations about the accuracy of NWP for high southern latitudes. Adams's (1997) study was based on the model output, for two summer seasons, from the European Centre for Medium-Range Weather Forecasts (ECMWF) model and from the Australian Bureau of Meteorology's Global Assimilation Prediction (GASP) model. Adams (1997) attributes the poor model performance observed to poor initialization analyses. This attribution has some support from Bromwich et al. (1999) who assessed National 


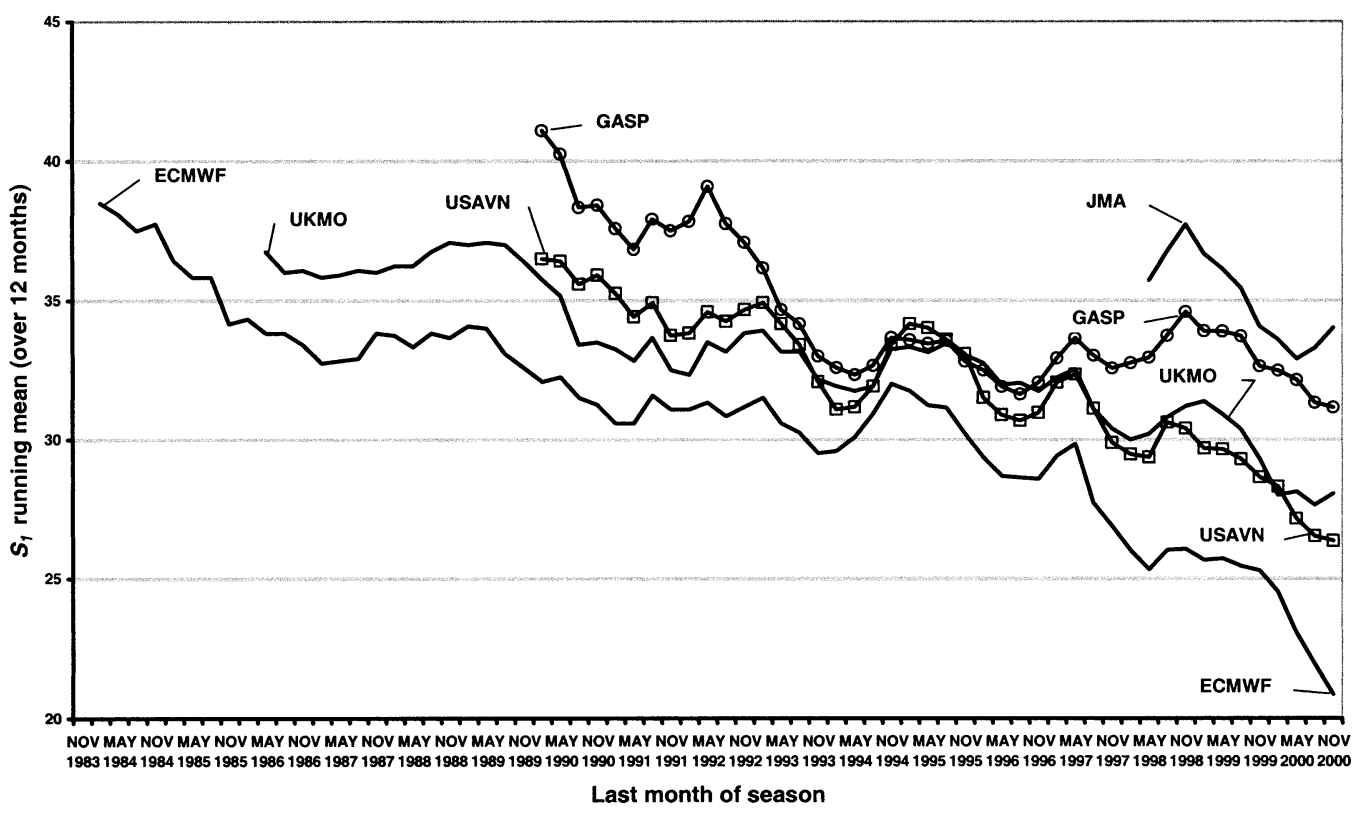

FIG. 1. Twelve-month running mean of the $S_{1}$ skill score for the prediction of the $500-\mathrm{hPa}$ height field at $72 \mathrm{~h}$ for the Australian region by various NWP models as labeled: ECMWF model, UKMO model, AVN, GASP, and JMA model. The unsmoothed data are for the period Oct 1984-May 2001, with the 12-month running means approximately centered on the last month of each season: every second end-of-season month is labeled. [The $S_{1}$ skill score is a measure (dimensionless) of the sum of the errors in the orthogonal $(x, y)$ gradients of the field in question, relative to the gradients in the forecast or verifying field, whichever is greater (Teweles and Wobus 1954; Seaman et al. 1993). The lower the value of $S_{1}$ the more skillful the forecast and for perfect forecasts, of the gradients, $S_{1}$ is zero; $S_{1}$ is a maximum of 200 when the forecast gradients are everywhere of equal size but of opposite sign to the observed gradients. A rule of thumb for predictions for the Australian region is that forecasts with an $S_{1}$ score above about 60 provide no useful skill in the prediction of the synoptic pattern.]

Centers for Environmental Prediction (NCEP) model analyses against FROST analyses and found that there was the suggestion that inaccurate model initial fields (particularly in the vertical temperature profile over continental Antarctica) have had a major role in producing the substantial model errors they found in some model fields.

On the other hand, Cullather et al. (1997) reported that, "The ECMWF analyses ... offer a reasonable depiction of the broad scale atmospheric circulation; however, deficiencies in mid-tropospheric temperatures and lower tropospheric winds are evident." Cullather et al. also noted a marked improvement in ECMWF and NCEP model analyses for the period 1985-94.

It is almost axiomatic that accurate NWP system prognoses will allow the forecaster to maximize the chances of correctly predicting the individual weather elements such as wind velocity. Bengtsson (1991) reported improvements in NWP systems and that, for the Southern Hemisphere taken as a whole, by the early 1990s the global models were producing "useful" forecasts out to 4-5 days ahead. Here "usefulness" was assessed using a common rule of thumb used within the ECMWF involving the anomaly correlation coefficient; the latter being the correlation over a large number of grid points (and usually over a large area such as a hemisphere) between forecast and observed departures from climatology. The rule used was that of useful prognoses achieving at least a $60 \%$ anomaly correlation coefficient. Strictly speaking, in applying standard regression analysis, the $70 \%$ level would be used to approximately explain half the variance in the forecast error; however, empirically, prognoses that achieved a $60 \%$ level were found to provide useful guidance to forecasters (see also Hollingsworth et al. 1980; Seaman et al. 1993).

Certainly in the Australian region (approximately between $15^{\circ}$ and $50^{\circ} \mathrm{S}$ and between $105^{\circ}$ and $170^{\circ} \mathrm{E}$ ) of the Southern Hemisphere the NWP models' skill has improved over time; Fig. 1 shows, for example, that the skill levels, as measured by the $S_{1}$ skill score (see the caption of Fig. 1 for a definition of $S_{1}$ ), of the various NWP models in predicting the 500-hPa field 3 days ahead, have steadily improved since the 1980s and early 1990s.

On the other hand, Fraedrich and Leslie (1991) suggested that, based on the time taken for errors in NWP 500-hPa fields to double in Antarctic areas of high baroclinicity, predictability timescales for discrete storms in high southern latitudes might be as short as about 1 day, whereas Baba (1993) suggested that at least a general trend in the local weather at Antarctic locations might be predicted well in advance in some circumstances. For example, Pendlebury and Reader (1993) 


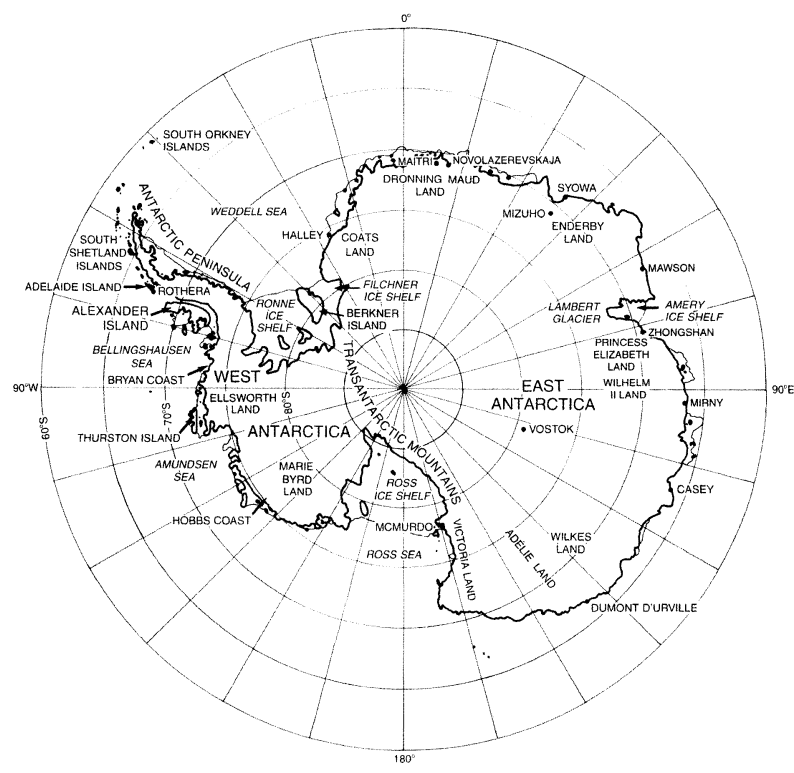

FIG. 2. A map of the Antarctic showing the principal regions and stations.

described the forecasting several days in advance by the ECMWF model of a very deep storm that affected Casey station $\left(66^{\circ} 17^{\prime} \mathrm{S}, 110^{\circ} 31^{\prime} \mathrm{E}\right.$; see the location map, Fig. 2) giving record wind gusts up to $66.9 \mathrm{~m} \mathrm{~s}^{-1}(130 \mathrm{kt})$ (see also Turner et al. 2001). Leonard et al. (1997) examined the performance of the United Kingdom Met Office (UKMO) model over the Antarctic and found that temperatures over the interior were too cold resulting in the katabatic winds being too strong, although in general they found that the model performed satisfactorily.

As may be inferred from Turner et al. (2000) and Turner and Pendlebury (2000), forecasting centers with Antarctic responsibilities increasingly have access to NWP output from a wide variety of global forecast mod- els, including ECMWF, UKMO, GASP, the NCEP Aviation Model (AVN), the Japanese Meteorological Agency (JMA) model, the German Deutscher Wetterdienst (DWD) model, and the U.S. Navy Operational Global Atmospheric Prediction System (NOGAPS). The aim of this paper is to examine the current status of the representativeness and accuracy of the analyses and prognoses that are available for high southern latitudes from the first five of these models, the broad configurations of which are shown in Table 1. By doing so, operational Antarctic forecasters might gain insights into how the models might be expected to perform, NWP model developers might gain insights into where improvements to the numerical systems might be needed, and climate researchers might be alerted to some model deficiencies that might affect climate inferences from the related general circulation models. In section 2 we examine aspects of the analyses, and in particular we look for differences between the various models. In section 3 we give a limited view of the skill of the current operational atmospheric models in predicting the mass fields and in the case of the GASP model we report on aspects of its handling of moisture. In section 4 we report on the contemporary views of operational Antarctic forecasters concerning how they assess the usefulness of NWP for weather forecasting in the Antarctic. In conclusion we touch on the potential that limited area modeling has in addressing some of the spatial-resolution problems that seem to limit the representativeness of global models.

\section{Global model analysis validation}

\section{a. Numerical analyses at $500 \mathrm{hPa}$ and MSLP analyses north of the continental interior}

The sparsity of data available for high southern latitudes may be appreciated through reference to Fig. 3, which shows a snapshot of surface observation sites (panel a) and radiosonde sites (panel b) available for

TABLE 1. Some models from which NWPs are operationally available for the Antarctic as of Oct 1999. For the spectral models the horizontal resolution given is the smallest half-wavelength resolved. A grid point model would need at least two grid points to resolve half a wave.

\begin{tabular}{|c|c|c|c|c|c|c|}
\hline Model & Type & $\begin{array}{c}\text { Horizontal } \\
\text { resolution }\end{array}$ & $\begin{array}{l}\text { No. of vertical } \\
\text { levels }\end{array}$ & $\begin{array}{l}\text { Forecast range } \\
\text { (h) }\end{array}$ & Analysis scheme & $\begin{array}{l}\text { Data cutoff } \\
\text { time }(\mathrm{h})\end{array}$ \\
\hline GASP & Spectral & $\begin{array}{l}\text { T239 } \\
(83 \mathrm{~km})\end{array}$ & 29 & 192 & MVSI & 6 \\
\hline ECMWF & Spectral & $\begin{array}{l}\text { T319 } \\
(62 \mathrm{~km})\end{array}$ & 31 & 168 & 4DVAR & 12 \\
\hline AVN & Spectral & $\begin{array}{c}\mathrm{T} 126 \\
(157 \mathrm{~km})\end{array}$ & 28 & 72 & SSI & 3 \\
\hline UKMO & Grid point & $\begin{array}{l}\text { 60-km grid } \\
\text { (approx) }\end{array}$ & 30 & 120 & 3DVAR & 3 \\
\hline JMA & Spectral & $\begin{array}{l}\mathrm{T} 213 \\
(93 \mathrm{~km})\end{array}$ & 30 & 168 & MVSI & 3 \\
\hline
\end{tabular}

MVSI: multivariate statistical interpolation.

SCM: successive correction method.

SSI: spectral statistical interpolation.

3DVAR: three-dimensional variational analysis.

4DVAR: four-dimensional variational analysis. 
a

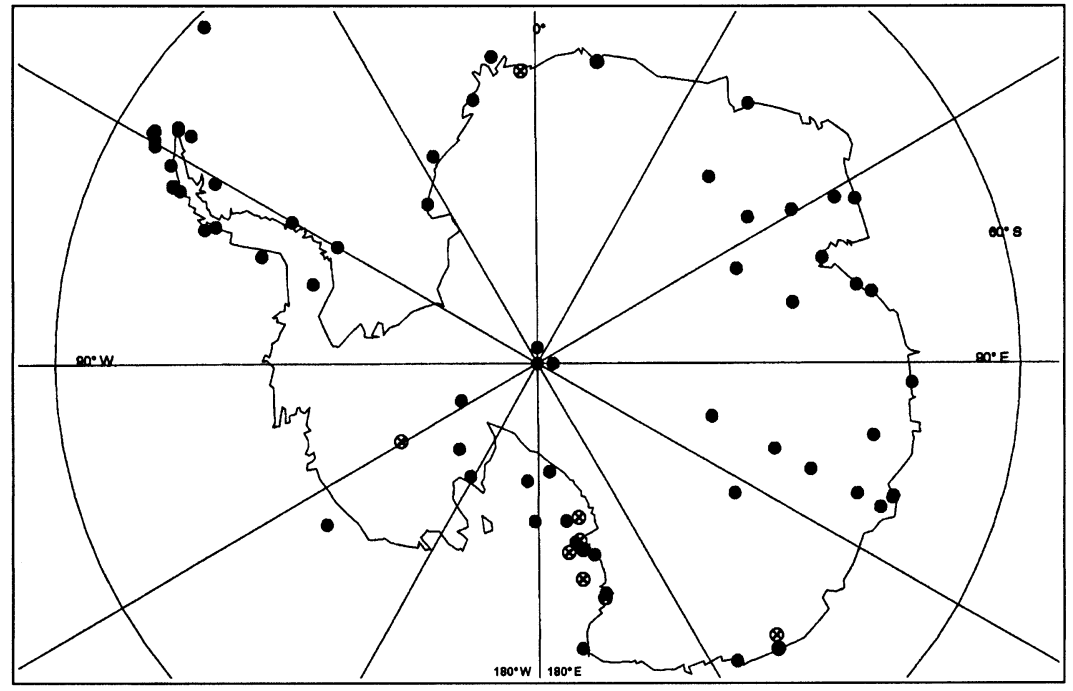

b

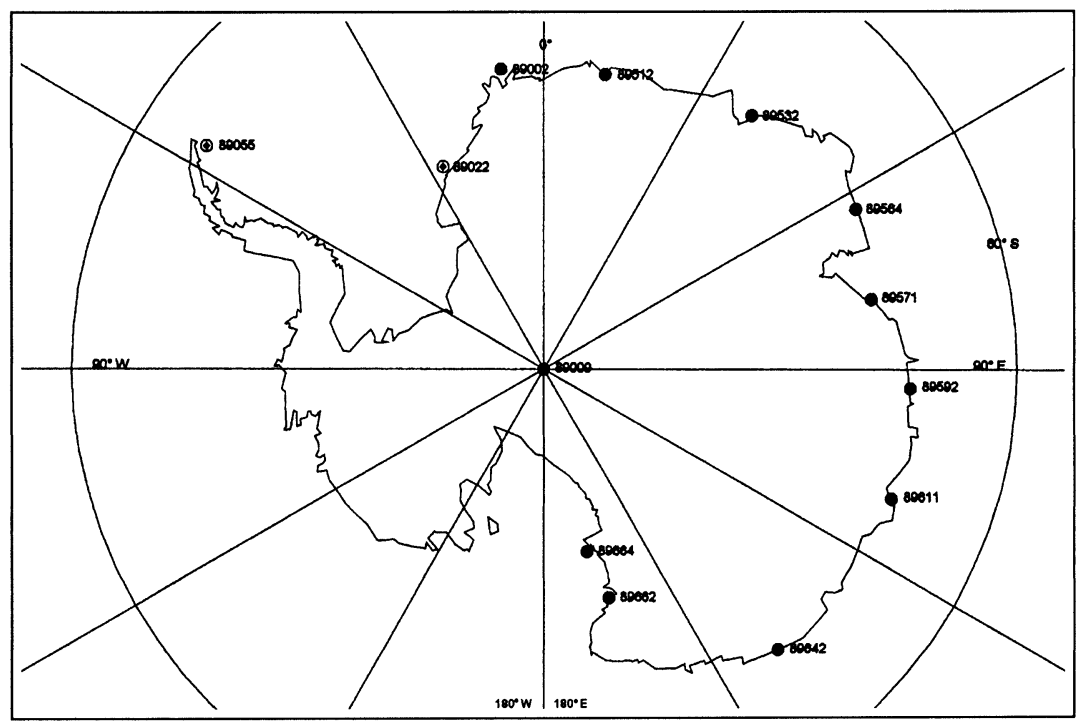

FIG. 3. Percentage of meteorological reports from the Antarctic for the period 1-15 Feb 2001: (a) the Antarctic Basic Synoptic Network at the main synoptic hours and (b) radiosonde data for 0000 and 1200 UTC (WMO station numbers shown). For both (a) and (b) the filled-in circles represent stations that reported between $50 \%$ and $100 \%$ of their observations for these times; the open circles with a central dot represent stations that reported between $1 \%$ and $50 \%$ of their observations for these times; and the open circles with an enclosed cross represent stations that did not report during the period.

the period 1-15 February 2001 (World Meteorological Organization 2001). Bearing in mind that of the stations/ sites shown in Fig. 3a over $10 \%$ did not report any observations during the period in question and not all of the others reported all observations, and that the upper air network is even more depleted in winter than shown in Fig. 3b, the scarcity of data begs the question: which model, if any, provides accurate analyses, let alone accurate prognoses? In addressing this question it is necessary to recognize that the height of the Antarctic continent makes reductions to mean sea level pressure (MSLP) problematical, and so the sea level pressure chart is not the best reference level for the continent itself (Schwerdtfeger 1984; Phillpot 1991; Pook and Cowled 1999). The first standard pressure level that does not intersect the Antarctic interior is the $500-\mathrm{hPa}$ level and that will be used as the level discussed over the continent while discussion of MSLP data will be restricted to areas north of the continental interior.

While not shown here in detail, where analysis data were available for comparison, the mean height differences at $500 \mathrm{hPa}$, and the differences in MSLP fields between four of the global numerical analysis systems, were examined for 1999. The models involved were the ECMWF, GASP, AVN, and the UKMO models. On a global basis it was found that generally speaking the 
(a)

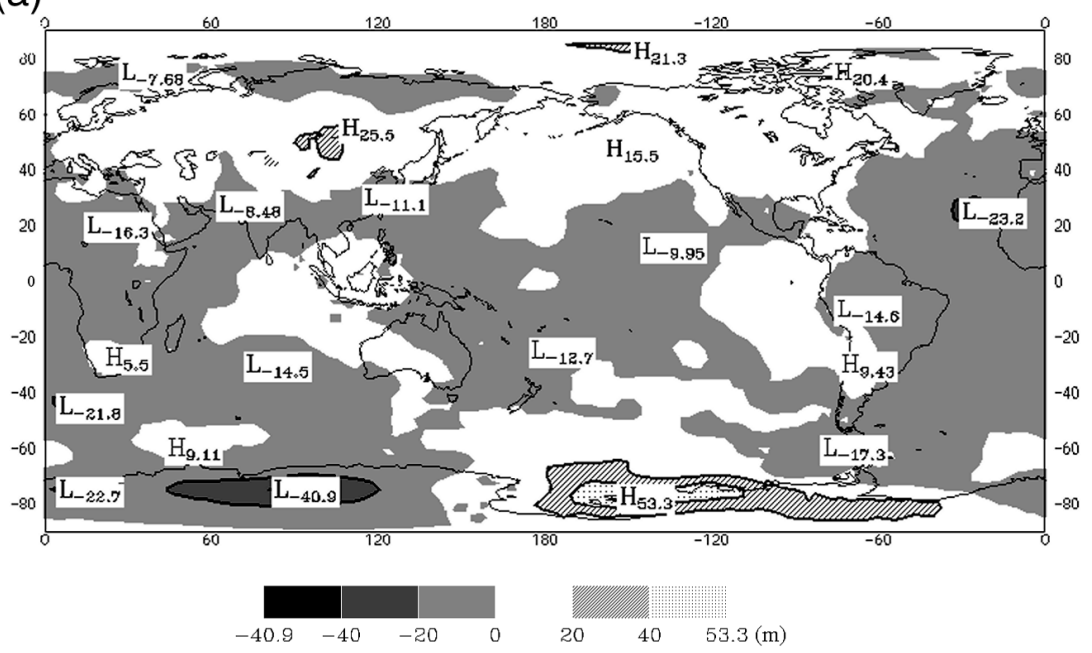

(b)

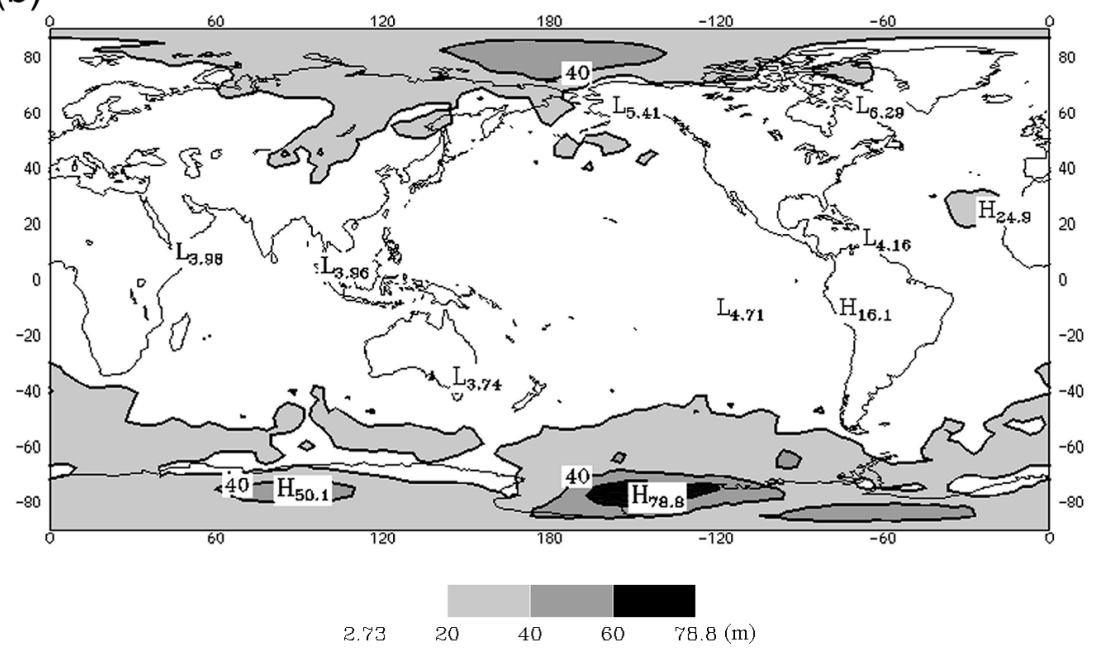

FIG. 4. (a) Mean geopotential height differences (m) (ECMWF minus UKMO) and (b) rms height differences (m), between the ECMWF and UKMO 500-hPa analyses at 1200 UTC for Jan 1999.

largest differences between models invariably occurred near to or over the Antarctic. The (Antarctic) locations of areas of model differences varied somewhat among the months examined, but generally speaking, where radiosonde data were more frequent (e.g., coastal regions of East Antarctica) model analysis differences at $500 \mathrm{hPa}$ were less than about $20 \mathrm{~m}$.

As an example, Fig. 4a shows the global mean daily 500-hPa geopotential height differences between the ECMWF and the UKMO analyses for January 1999, while Fig. 4b shows the January 1999 root-mean-square (rms) differences in 500-hPa geopotential heights between these models. The largest differences for this month occurred near the Antarctic coast at about $140^{\circ} \mathrm{W}$ where, on average, the ECMWF analyses were up to around $53 \mathrm{~m}$ higher than the UKMO analyses (Fig. 4a). While not shown, some other January 1999 mean daily differences in 500-hPa height contour analyses for this location include the following: the GASP model analyses were $130 \mathrm{~m}$ or so lower than the ECMWF analyses, the GASP analyses were about $90 \mathrm{~m}$ less than the UKMO analyses, while the AVN analyses were, on average, within $20 \mathrm{~m}$ of the UKMO model at this location.

While these types of comparisons do not prove which analysis model is the most accurate they do highlight the differences between model systems, either in the way they treat the data, or in the cutoff times for data reception. This point is relevant when one comes to examine prognosis verifications since a standard technique is for NWP model's prognostic fields to be verified against its own analyses. Moreover, the size of these differences may have a bearing on some of the physical parameters that might be computed in a daily and climate sense. For example, from Fig. 4b, the rms height 
(a)

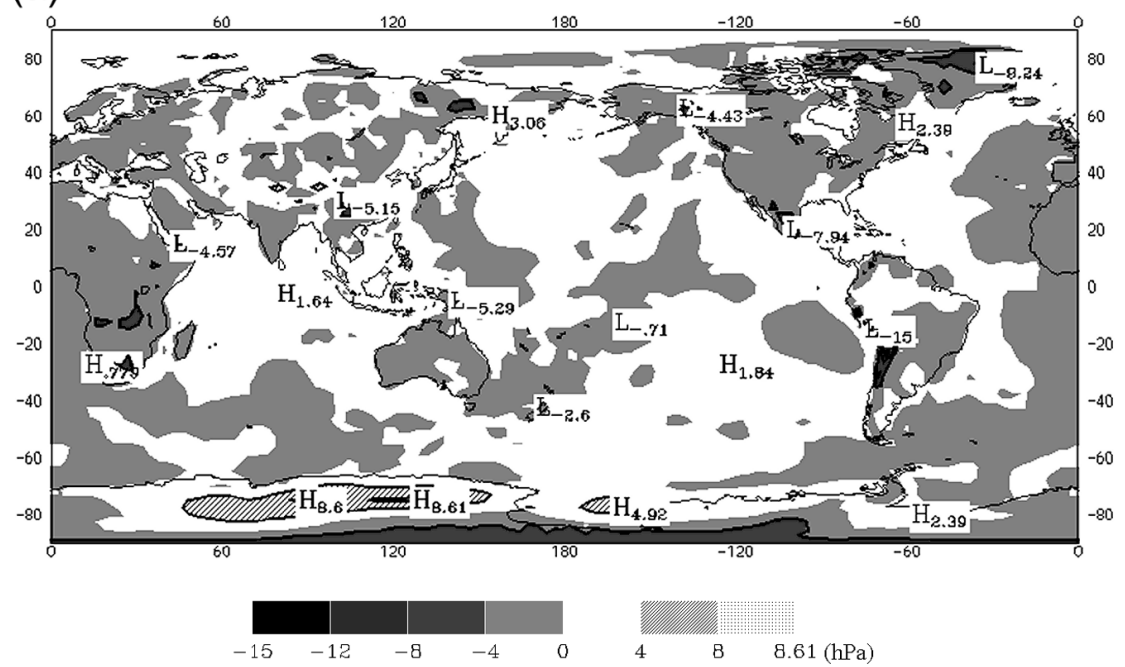

(b)
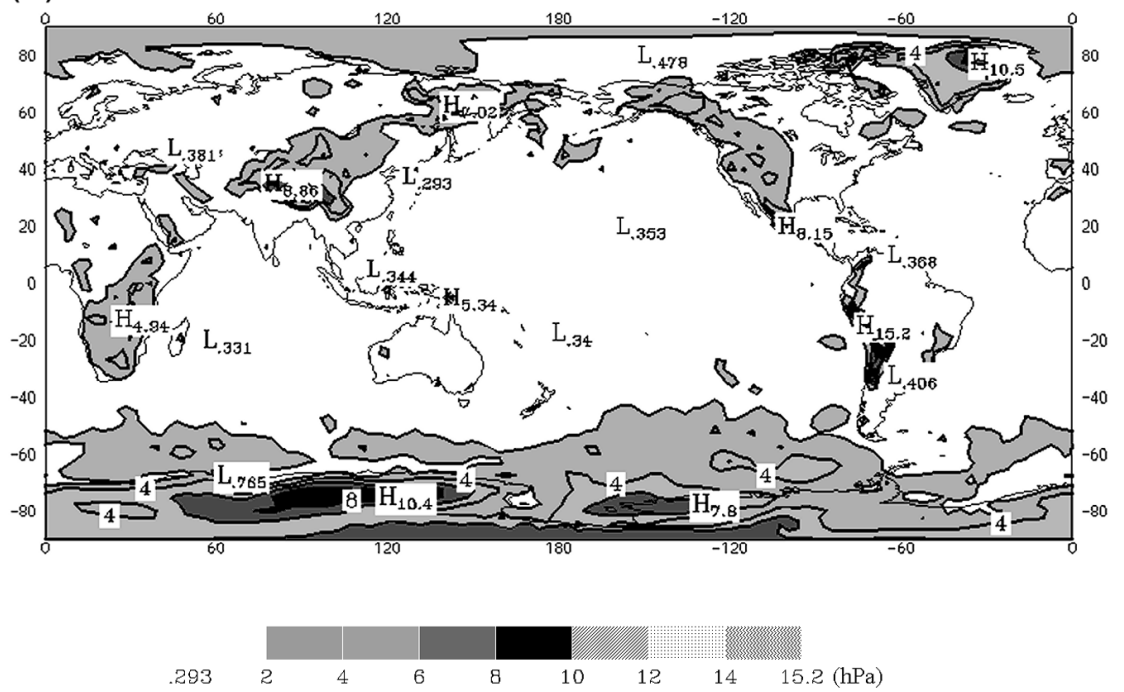

FIG. 5. (a) Mean MSLP differences (hPa) and (b) rms differences (hPa) between the ECMWF and UKMO MSLP analyses at 1200 UTC for Jan 1999.

difference along $75^{\circ} \mathrm{S}$ between $170^{\circ} \mathrm{E}$ and $150^{\circ} \mathrm{W}$ is about $60 \mathrm{~m}$, which after comparison with Fig. 4a indicates that, in relative terms, the January 1999 ECMWF analyses generated a northerly geostrophic wind flow over this area at $500 \mathrm{hPa}$ of about $4 \mathrm{~m} \mathrm{~s}^{-1}$ or more, on at least about one-third of the occasions when compared to the UKMO analyses. And so for moisture and heat transport studies (e.g., Hines et al. 1999; Bromwich et al. 2000) the two models would give somewhat different values of these parameters. Until further detailed validation studies are undertaken using observational data, one is tempted to assume that, based on Cullather et al. (1997), the ECMWF analyses are the most superior.

The differences among the operational analyses may also reflect the relative scarcity of observations. Each individual observation can have considerable impact.
The mean and rms January 1999 examples presented here for both 500-hPa geopotential height (Figs. 4a and 4b) and MSLP (Figs. 5a and 5b) show minimum differences along most of the Antarctic coast from the Antarctic Peninsula through the Eastern Hemisphere to the Ross Sea where there are more observations, but with large differences along the Western Hemisphere coast and adjacent ocean area (disregarding the MSLP differences over the continental interior) where observations are more sparse. This demonstrates the importance of the in situ observations.

Moreover, as mentioned, the comparison of analyses of $500-\mathrm{hPa}$ height consistently shows the largest differences for the whole globe occur over the Antarctic continent. Few operational systems use Television and Infrared Observation Satellite (TIROS) Operational 
Vertical Sounder (TOVS) data at low levels over land areas, including the Antarctic continent, and Amundsen-Scott station at the South Pole is currently the only upper air observing station in the elevated interior of the continent. Communications difficulties as noted by Cullather et al. (1997) restrict the availability of the observations for operational use. So it is not surprising that even at the South Pole significant differences (not shown) can occur in analyses although generally smaller than some areas of the continent. The differences in data cutoff times could be a factor here, with the U.S. and U.K. systems less likely to have the data with their short cutoff times (Table 1).

The extensive coverage of satellite-based observations such as cloud drift winds, scatterometer measurements of surface wind speed and direction over the ocean, and high-density soundings of temperature and moisture may belie the Southern Hemisphere's reputation as a data-sparse area. However, NWP skill is still lower for the Southern Hemisphere than it is for the Northern Hemisphere, although the gap is narrowing (e.g., Kalnay et al. 1998). The reason in part is that much of the satellite data provide information on gradients of the thermal structure of the atmosphere rather than absolute values. Where there are no pressure measurements from nearby coastal stations the drifting buoys with pressure sensors provide sparse referencelevel information. The rms charts also show that over the ocean areas along the coast of West Antarctica the pattern of rms differences at $500 \mathrm{hPa}$ is correlated with MLSP: a correlation that suggests that defining the surface pressure is still an issue for operational analyses.

As a by-product of the models' analysis and assimilation systems (e.g., Seaman et al. 1995), information is available on the "impact" of individual data platforms and types (Seaman 1994), as measured by the difference in the analysis with and without particular observations. Such impacts can be conveniently calculated within a statistical interpolation data assimilation system. This measure of impact is not the same as a total data denial impact, and depends on factors such as the weight given to the observation type in the analysis system and the spatial and temporal variability of the field being analyzed.

Table 2 shows the 10 Southern Hemisphere surface observation sources having the highest rms impact (as defined above) on the GASP analyses for June-September 1999. The results are based on evaluating the impact for all surface synoptic observations (surface synoptic stations, ship, or buoy) in the Southern Hemisphere and are based on ensemble statistics of rms impacts. Only stations below $800 \mathrm{~m}$ are considered so that impacts can all be taken as applying to sea level pressure.

The results show that the stations having the highest impact on the GASP analyses are all isolated stations at high latitudes and mostly close to or inside the Ant-
TABLE 2. Average impact on the GASP analysis of MSLP for Jul-Sep 1999.

\begin{tabular}{lccccrr}
\hline \hline \multirow{2}{*}{$\begin{array}{c}\text { Station name } \\
\text { or drifting } \\
\text { buoy no. }\end{array}$} & \multicolumn{2}{c}{ Location } & & \multicolumn{2}{c}{ Impact (hPa) } \\
\cline { 2 - 3 } \cline { 5 - 6 } \cline { 5 - 6 } & Lat & Lon & & Rms & Max \\
\hline 71557 & $66^{\circ} \mathrm{S}$ & $306^{\circ} \mathrm{E}\left(54^{\circ} \mathrm{W}\right)$ & & 3.1 & 9.6 \\
Grytviken & $54^{\circ} \mathrm{S}$ & $324^{\circ} \mathrm{E}\left(36^{\circ} \mathrm{W}\right)$ & & 3.0 & 7.0 \\
Orcadas & $61^{\circ} \mathrm{S}$ & $315^{\circ} \mathrm{E}\left(45^{\circ} \mathrm{W}\right)$ & & 2.9 & 7.5 \\
71552 & $70^{\circ} \mathrm{S}$ & $285^{\circ} \mathrm{E}\left(75^{\circ} \mathrm{W}\right)$ & & 2.5 & 10.8 \\
56549 & $56^{\circ} \mathrm{S}$ & $105^{\circ} \mathrm{E}$ & & 2.4 & 9.6 \\
74531 & $66^{\circ} \mathrm{S}$ & $355^{\circ} \mathrm{E}$ & & 2.3 & 10.2 \\
56541 & $62^{\circ} \mathrm{S}$ & $173^{\circ} \mathrm{E}$ & & 2.3 & 10.2 \\
74532 & $55^{\circ} \mathrm{S}$ & $106^{\circ} \mathrm{E}$ & & 2.3 & 6.6 \\
Crozet Island & $46^{\circ} \mathrm{S}$ & $52^{\circ} \mathrm{E}$ & & 2.1 & 6.5 \\
Belgrano & $78^{\circ} \mathrm{S}$ & $302^{\circ} \mathrm{E}\left(58^{\circ} \mathrm{W}\right)$ & & 2.0 & 8.0 \\
\hline
\end{tabular}

arctic Circle. This indicates the value of each individual observation and the lack of redundancy in the observation coverage for the region.

Similar calculations are carried out routinely for Australian region upper air observations. These show that Macquarie Island $\left[54^{\circ} 25^{\prime} \mathrm{S}, 158^{\circ} 58^{\prime} \mathrm{E}\right.$, approximately $1600 \mathrm{~km}$ north of the coast of East Antarctica (Fig. 2)] has the highest impact for wind and geopotential height in the troposphere. Its impact falls off at the 200-hPa level, which is generally above the tropopause at this latitude. The impact is generally almost double that of the station with the next highest impact-despite the availability of complementary TOVS data over the sea, which is not used at low levels over land (see Table 2).

\section{b. Site-specific performance of the GASP model analyses: Some examples from East Antarctica}

The following provides some information on how the GASP model analysis scheme represents conditions at three East Antarctic stations: Casey, Davis (68 $36^{\prime} \mathrm{S}$, $\left.78^{\circ} 0^{\prime} \mathrm{E}\right)$, and Mawson $\left(67^{\circ} 36^{\prime} \mathrm{S}, 62^{\circ} 53^{\prime} \mathrm{E}\right)$. Time series of observed and modeled surface and upper air parameters were prepared for the calendar year 2000. Due to space limitations, examples presented here are confined to the surface parameter observations for Mawson for the second half of 2000 and the corresponding time series of the GASP data for the model grid point closest to Mawson (Fig. 6), this grid point being chosen as the best representation of the station in relation to the smoothed model ground slope and coast. And Figs. 7 and 8 are, respectively, vertical cross-sectional radiosonde relative humidity observations, and model data for Mawson for the year 2000. Inferences from the time series for these three stations, about the GASP model's ability to represent the real atmosphere during its analysis cycle include the following.

- Surface wind velocity is well diagnosed on some occasions (e.g., the storm conditions at the end of August) but poorly handled on others (e.g., most of July) (Figs. 6a and 6b). Overall, trends are rea- 

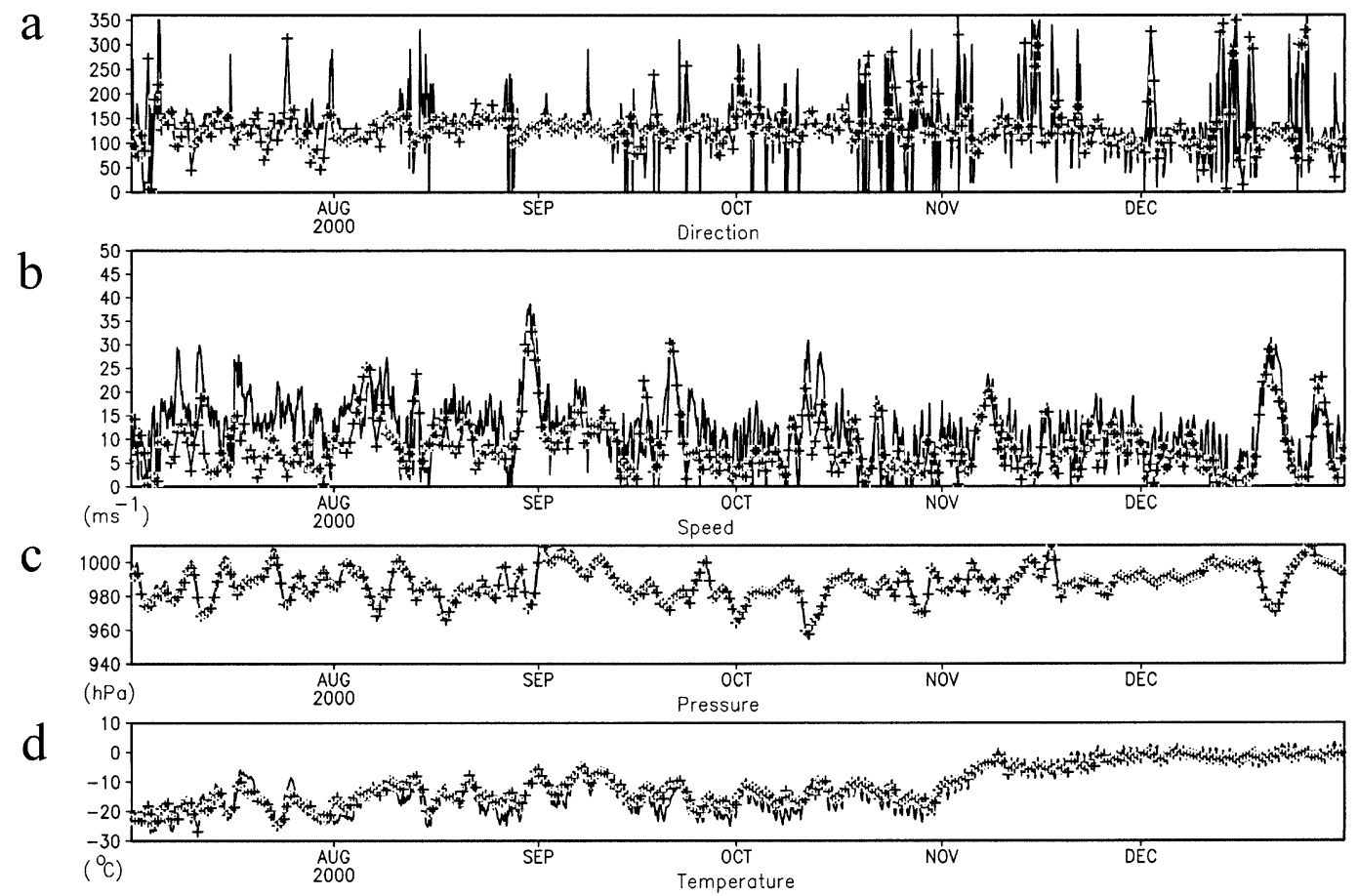

FIG. 6. Time series of observed surface data at Mawson (solid line) and time series of GASP model analysis surface data for Mawson (lighter line with + symbols) for 1 Jul-31 Dec 2000: (a) wind direction, (b) wind speed, (c) station level pressure, and (d) screen temperature.

sonably well represented, in that, by inspection the major peaks in observed wind speed appear to be replicated by peaks in the diagnosed model speed. However, the magnitude of the wind speed is often underestimated, especially at Mawson (Figs. 6a and $6 b)$, where the katabatic wind is a feature of the local climatology. This behavior is not entirely unexpected, as wind is not directly assimilated into the GASP model.

- Surface pressure is handled very well by GASP's as-

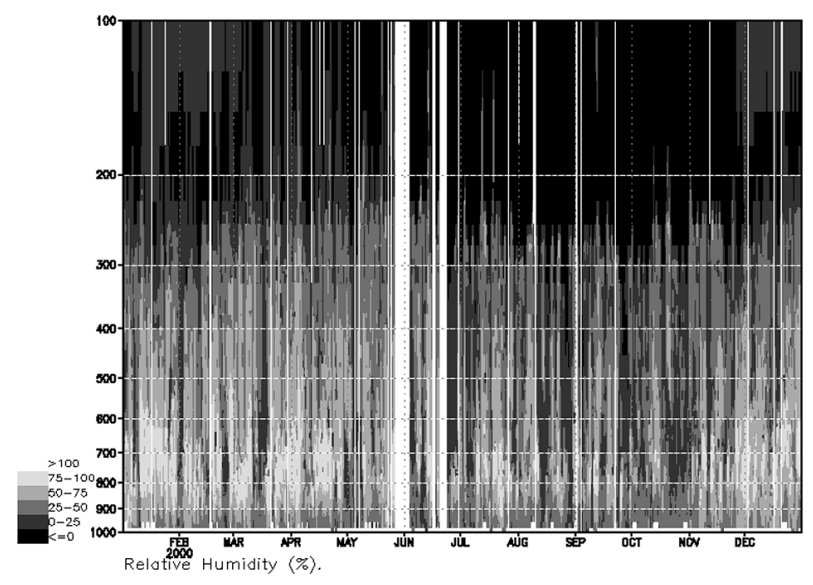

FIG. 7. Observed cross-sectional relative humidity data (\%) for Mawson for 2000. [The left-hand scale is pressure (hPa).] similation scheme, as it should be because surface pressure is directly assimilated into the model. The slight negative bias shown in Fig. $6 c$ is thought to be due to the model grid point being slightly seaward of the station.

- Surface temperature is represented reasonably well although the magnitude and phase of synoptic-induced variations are not always exactly matched by the model data; note for example the July-September period in Fig. 6d.

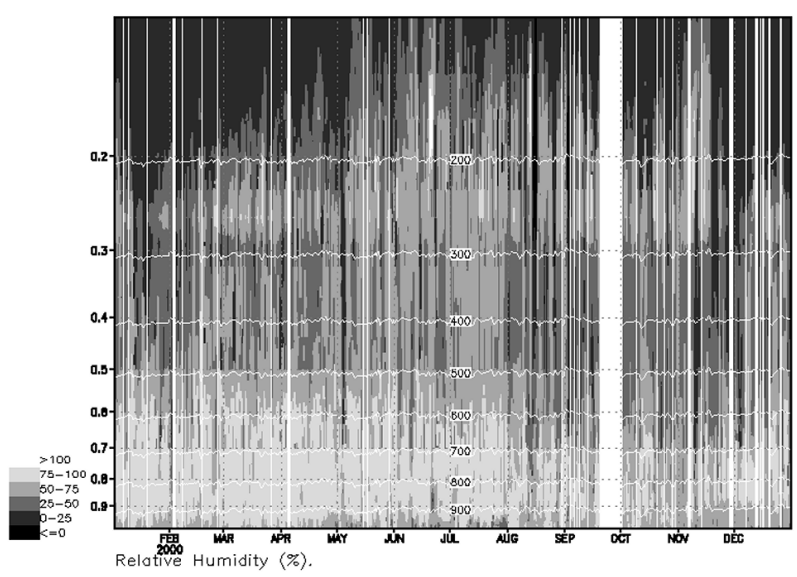

FIG. 8. GASP model analysis cross-sectional relative humidity data for Mawson for 2000. [The left-hand scale is sigma level, while the approximately horizontal lines are pressure (hPa).] 
- Upper air wind and temperature data are better assimilated across all fields than are the surface data.

- Upper-level wind directions are well modeled, although they are sometimes a few degrees different from the observed data.

- Upper-level wind speeds are only marginally less in the GASP analyses than observed.

- Upper-level moisture is not so well assimilated with GASP seeming to be too moist-especially above 250 hPa (cf., e.g., Figs. 7 and 8).

- Even in the surface layers the GASP analyses are not representing the dry events well and are carrying too much moisture.

- The dry events that the GASP model does capture tend not to be as dry as reality or as long lived. The model seems to want to increase moisture rapidly: this is discussed further in section $3 \mathrm{~d}$.

\section{An overview of global model performance in high southern latitudes from bulk statistics}

\section{a. 500-hPa forecast fields}

There are many NWP products that can be used to objectively compare the various models but until the spatial resolution of the global models is improved there may not be a great deal to be gained by exhaustive comparisons of each of these. A simple approach is to examine the relative performance of the models at predicting the 500-hPa level. This is relevant given that, as mentioned, the $500-\mathrm{hPa}$ surface is the first standard atmospheric level that does not intersect the Antarctic continent. Moreover, in an operational sense, the 500$\mathrm{hPa}$ field has some direct use for forecasting surface weather through pattern recognition of analogs in the absence of detailed NWP guidance (Phillpot 1997).

\section{b. Improved NWP performance during the last decade}

An earlier reference to Fig. 1 alluded to an improving trend in NWP performance over the Australian region since the mid-1980s, at least at the $+72 \mathrm{~h}$ models' time step. In particular it may be noted from Fig. 1 that from the austral summer of 1998/99 and onward the skill levels of all the models considered have improved in an almost monotonic sense, even allowing for seasonal cycles in the $S_{1}$ statistic. The likely factors in this improvement are the introduction of data from the Advanced Microwave Sounding Unit (AMSU) instrument on board the National Oceanic and Atmospheric Administration-15 (NOAA-15) satellite, better use of satellite radiance data in the analysis systems through direct use of radiances rather than derived temperature profiles, and continued enhancements in model resolution, both horizontal and vertical. For ECMWF a major system change was the implementation of the four- dimensional variational (4DVAR) analysis scheme in December 1997.

To ascertain if similar improvements were occurring over high southern latitudes, rms errors and $S_{1}$ skill score statistics for the ECMWF, GASP, JMA, UKMO, and AVN models' ability to predict 500 -hPa heights at $55^{\circ} \mathrm{S}$, and south thereof (herein defined for convenience as high southern latitudes), were examined for all readily available (i.e., to the authors) data from November 1994 to May 2001 inclusive. Figure 9 shows unsmoothed monthly $S_{1}$ skill scores for the ECMWF, UKMO, and GASP NWP $+72 \mathrm{~h}$ prediction of 500-hPa heights over high southern latitudes for all months from November 1994 to May 2001 inclusive. For clarity of presentation, data for the AVN and JMA models were not included in the figure; however, Table 3 lists annual averages of the $S_{1}$ skill score and rms errors in 500-hPa height prediction for each of the five models being discussed here, for 24 -h time steps from +24 to $+168 \mathrm{~h}$ inclusive. It may be inferred from Fig. 9 and from Table 3 that the trends shown in Fig. 1 are applicable to high southern latitudes, namely, NWP models are improving over time and that the ECMWF model is clearly the most successful model at 500-hPa-height prediction, with the UKMO and AVN models next, and the GASP and JMA models lagging in accuracy. Interestingly, from Table 3 , it may be noted that as the forecast time step increases the models tend toward a common level of inaccuracy, perhaps indicating that by $168 \mathrm{~h}$ a limit in skill has been approached. This inference is somewhat supported by visual inspection of Fig. 10, which shows unsmoothed monthly rms errors for the ECMWF model 500-hPaheight prediction over high southern latitudes for forecast time steps from 24 to $168 \mathrm{~h}$ and for all months from November 1994 to May 2001 inclusive: while there is a clear trend of reducing rms errors in all time steps of $144 \mathrm{~h}$, or less, the trends are less convincing at $168 \mathrm{~h}$. On the other hand it is of interest that average rms errors in ECMWF $+72 \mathrm{~h} 500-\mathrm{hPa}$ height field prognoses for the calendar year 2000, for example, were close to $50 \mathrm{~m}$, compared to similar errors in the $+48 \mathrm{~h}$ prognoses in 1995. Similar relative improvements may be noted for all time steps out to $+144 \mathrm{~h}$ indicating a day's gain in "predictability" since the mid-1990s.

\section{c. A more detailed look at recent NWP of the 500- hPa height field}

Rms errors, bias, $S_{1}$ skill score, and anomaly correlation statistics for the ECMWF, GASP, JMA, UKMO, and AVN models' ability to predict $500-\mathrm{hPa}$ heights south of $55^{\circ} \mathrm{S}$ were examined on a quarterly basis for the calendar year 2000. Again, in each case the NWP model was verified against its own analysis. Figure 11 shows the results for the third quarter of 2000 (JulySeptember inclusive) and is typical of the data for the other quarters of 2000 in that the ECMWF model clearly had the most skill (panel a), the lowest rms errors (panel 
TABLE 3. Mean annual $S_{1}$ skill score and rms error $(\mathrm{m})$ statistics for some models from which NWPs are operationally available for the Antarctic.

\begin{tabular}{|c|c|c|c|c|c|c|c|c|c|c|c|}
\hline \multicolumn{12}{|c|}{ Numerical model } \\
\hline \multirow{2}{*}{$\begin{array}{l}\text { Time } \\
\text { step }\end{array}$} & \multirow[b]{2}{*}{ Year } & \multicolumn{2}{|c|}{ GASP } & \multicolumn{2}{|c|}{ JMA } & \multicolumn{2}{|c|}{ UKMO } & \multicolumn{2}{|c|}{ AVN } & \multicolumn{2}{|c|}{ ECMWF } \\
\hline & & $S_{1}$ & Rms & $S_{1}$ & Rms & $S_{1}$ & Rms & $S_{1}$ & $\mathrm{Rms}$ & $S_{1}$ & Rms \\
\hline \multirow[t]{7}{*}{$+24 \mathrm{~h}$} & 1995 & 31.2 & 40.6 & & & 20.7 & 26.5 & 21.7 & 30.6 & 23.2 & 28.7 \\
\hline & 1996 & 30.6 & 38.3 & & & 21.8 & 28.6 & 23.4 & 29.9 & 21.1 & 26.0 \\
\hline & 1997 & 31.5 & 40.1 & & & 21.2 & 28.5 & 25.4 & 31.5 & 21.8 & 28.0 \\
\hline & 1998 & 32.8 & 40.4 & 25.4 & 33.5 & 21.1 & 28.8 & 22.3 & 28.2 & 19.7 & 23.9 \\
\hline & 1999 & 27.1 & 35.1 & 22.7 & 31.9 & 21.5 & 28.4 & 23.2 & 27.3 & 17.6 & 21.4 \\
\hline & 2000 & 25.6 & 30.6 & 25.5 & 31.3 & 20.5 & 23.4 & 20.9 & 23.3 & 15.2 & 16.9 \\
\hline & 3-yr avg & 28.5 & 35.4 & 24.5 & 32.2 & 21.0 & 26.9 & 22.1 & 26.3 & 17.5 & 20.7 \\
\hline \multirow[t]{7}{*}{$+48 \mathrm{~h}$} & 1995 & 42.4 & 62.2 & & & 34.8 & 46.9 & 36.3 & 53.2 & 37.0 & 48.8 \\
\hline & 1996 & 41.8 & 59.3 & & & 37.4 & 52.9 & 37.8 & 52.2 & 34.8 & 46.3 \\
\hline & 1997 & 42.7 & 60.3 & & & 36.9 & 52.4 & 38.9 & 52.8 & 34.9 & 49.4 \\
\hline & 1998 & 44.1 & 59.8 & 40.9 & 58.6 & 36.0 & 52.0 & 37.4 & 50.6 & 32.0 & 42.4 \\
\hline & 1999 & 40.3 & 56.8 & 38.7 & 57.4 & 34.9 & 50.1 & 36.2 & 46.4 & 29.7 & 38.9 \\
\hline & 2000 & 39.6 & 51.7 & 40.3 & 54.4 & 33.1 & 41.4 & 35.6 & 41.9 & 27.4 & 33.3 \\
\hline & 3 -yr avg & 41.3 & 56.1 & 40.0 & 56.8 & 34.7 & 47.8 & 36.4 & 46.3 & 29.7 & 38.2 \\
\hline \multirow{7}{*}{$+72 \mathrm{~h}$} & 1995 & 49.8 & 81.2 & & & 45.8 & 69.3 & 47.2 & 75.1 & 47.3 & 72.2 \\
\hline & 1996 & 49.7 & 77.5 & & & 49.6 & 75.9 & 48.5 & 72.9 & 45.5 & 68.9 \\
\hline & 1997 & 50.0 & 77.5 & & & 48.7 & 74.3 & 49.6 & 71.8 & 45.0 & 69.4 \\
\hline & 1998 & 51.3 & 75.2 & 51.6 & 82.2 & 47 & 74.3 & 48.3 & 71.5 & 41.6 & 62.3 \\
\hline & 1999 & 45.2 & 75.3 & 46.3 & 80.0 & 41.6 & 70.0 & 42.4 & 65.3 & 35.9 & 56.9 \\
\hline & 2000 & 49.4 & 72.6 & 50.7 & 75.3 & 43.3 & 60.3 & 46.7 & 61.0 & 38.2 & 51.4 \\
\hline & 3-yr avg & 48.6 & 74.4 & 49.5 & 79.2 & 44.0 & 68.2 & 45.8 & 65.9 & 38.6 & 56.9 \\
\hline \multirow[t]{7}{*}{$+96 \mathrm{~h}$} & 1995 & 55.2 & 97.8 & & & 54.3 & 88.9 & & & 54.7 & 91.4 \\
\hline & 1996 & 55.9 & 96.4 & & & 58.5 & 98.5 & & & 53.6 & 89.7 \\
\hline & 1997 & 55.4 & 92.9 & & & 56.3 & 94.7 & & & 52.5 & 89.2 \\
\hline & 1998 & 56.8 & 90.2 & 59.1 & 100.8 & 54.7 & 94.5 & & & 49.7 & 81.8 \\
\hline & 1999 & 54.9 & 92.2 & 57.4 & 100.6 & 51.2 & 87.9 & & & 47.3 & 76.8 \\
\hline & 2000 & 57.5 & 90.9 & 57.8 & 93.0 & 51.4 & 79.6 & & & 47.4 & 70.2 \\
\hline & 3-yr avg & 56.4 & 91.1 & 58.1 & 98.1 & 52.4 & 87.3 & & & 48.1 & 76.3 \\
\hline \multirow[t]{7}{*}{$+120 \mathrm{~h}$} & 1995 & 59.7 & 111.3 & & & 60.5 & 106.8 & & & 60.2 & 109.1 \\
\hline & 1996 & 60.8 & 109.2 & & & 65.0 & 116.6 & & & 59.6 & 107.9 \\
\hline & 1997 & 60.7 & 107.3 & & & 62.6 & 111.4 & & & 58.3 & 106.2 \\
\hline & 1998 & 60.7 & 102.4 & 64.4 & 117.9 & 59.6 & 110.7 & & & 56.1 & 99.6 \\
\hline & 1999 & 59.7 & 107.4 & 62.5 & 116.9 & 56.6 & 105.2 & & & 53.9 & 94.7 \\
\hline & 2000 & 62.0 & 106.3 & 63.0 & 108.1 & 58.6 & 97.9 & & & 54.6 & 89.3 \\
\hline & 3 -yr avg & 60.8 & 105.4 & 63.3 & 114.3 & 58.5 & 104.6 & & & 55.0 & 94.5 \\
\hline \multirow[t]{7}{*}{$+144 \mathrm{~h}$} & 1995 & 62.2 & 122.9 & & & & & & & 64.2 & 123.6 \\
\hline & 1996 & 64.4 & 122.1 & & & & & & & 64.3 & 123.7 \\
\hline & 1997 & 63.8 & 120.5 & & & & & & & 62.7 & 120.6 \\
\hline & 1998 & 64.0 & 113.0 & 67.4 & 130.1 & & & & & 61.5 & 116.5 \\
\hline & 1999 & 63.1 & 120.5 & 66.4 & 130.2 & & & & & 59.1 & 111.3 \\
\hline & 2000 & 65.8 & 117.9 & 66.9 & 121.8 & & & & & 60.7 & 107.1 \\
\hline & 3-yr avg & 64.3 & 117.1 & 66.9 & 127.0 & & & & & 60.4 & 111.6 \\
\hline \multirow{3}{*}{$+168 \mathrm{~h}$} & 1995 & 64.5 & 132.3 & & & & & & & & \\
\hline & 1996 & 67.6 & 133.1 & & & & & & & & \\
\hline & 1997 & 66.4 & 129.9 & & & & & & & & \\
\hline
\end{tabular}




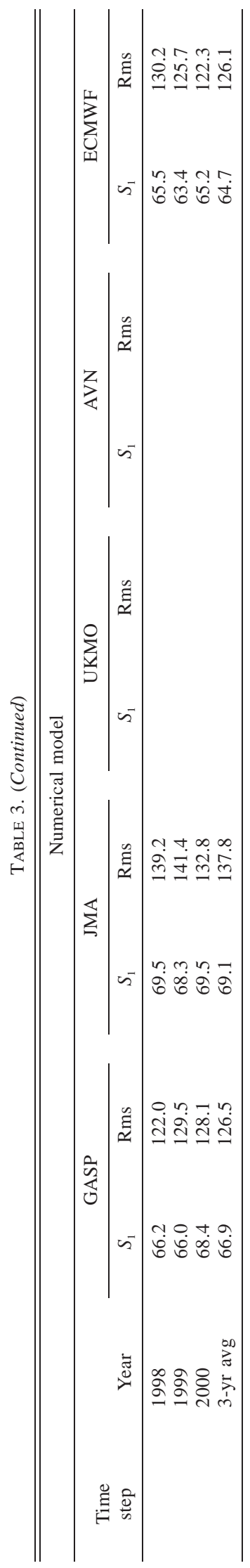

b), and stayed above the anomaly correlation coefficient threshold for predictability of $60 \%$ for the longest forecast period (in excess of $168 \mathrm{~h}$ ). On the other hand, while for the quarter shown in Fig. 11c the ECMWF model bias at $500 \mathrm{hPa}$ grew more over time than did all the other model biases (except GASP) this behavior was not consistent throughout the year. In the OctoberDecember quarter (not shown due to space limitations), for example, the ECMWF bias was the least of all the models and remained near zero even at $168 \mathrm{~h}$. Moreover, it would appear that, overall, the biases in $500-\mathrm{hPa}-$ height prediction were small for all of the models (on the order of no more than about $20 \mathrm{~m}$ ) and random.

Figure 11 is also typical of the other quarters of the year 2000 in that the UKMO and AVN were on a par in terms of overall performance, but clearly ahead of the GASP and JMA models - these last two also being on a par with each other. The results highlight the inference of the overall superiority of the ECMWF model as a forecast model: this complements the inference from Cullather et al. (1997) that the ECMWF analyses are the most superior.

Based on the above assessments it is instructive to examine examples of ECMWF performance. As an example, global charts of the $500-\mathrm{hPa}$ forecast mean and rms error for the ECMWF prognoses at 24, 48, 72, and $120 \mathrm{~h}$ for January 1999 were examined (Figs. 12 and 13, respectively; the 120-h charts are not shown for space reasons). At $24 \mathrm{~h}$ the prognosis mean height errors (when compared against the ECMWF analyses) were everywhere less than $20 \mathrm{~m}$. By $120 \mathrm{~h}$ maximum errors over the Antarctic had increased to about $70 \mathrm{~m}$. Examination of similar mean prognoses for other models suggests that, for January 1999 at least, at $24 \mathrm{~h}$, the GASP model errors were comparable with the ECMWF prognosis at $72 \mathrm{~h}$ (which compares well with the data in Fig. 11), the UKMO model errors at $24 \mathrm{~h}$ were comparable with the ECMWF errors at $48 \mathrm{~h}$, and the AVN at $48 \mathrm{~h}$ had errors that were also comparable with the ECMWF errors at $48 \mathrm{~h}$.

Bearing in mind the differences in analyses that were discussed earlier, it may be that some of these comparisons are generous. In the case of the GASP model, for example, it was noted that near the Antarctic coast at about $140^{\circ} \mathrm{W}$ the average difference in 500 -hPa-height contour analysis between the GASP and the ECMWF models for January 1999 gave a peak value of the GASP analysis being $134 \mathrm{~m}$ lower than the ECMWF analysis. If the ECMWF analysis were taken as the "truth," then the GASP prognosis would be in error by a much greater amount than mentioned above.

Figures 12 and 13 are also of interest in highlighting aspects of the ECMWF's skill at 500-hPa prediction, assuming its analyses to be reasonably representative of the atmosphere at $500 \mathrm{hPa}$. The greatest mean errors in the ECMWF 500-hPa height field for January 1999 were over the Antarctic: the positive bias perhaps suggesting that the processes in the model Antarctic land-atmo- 


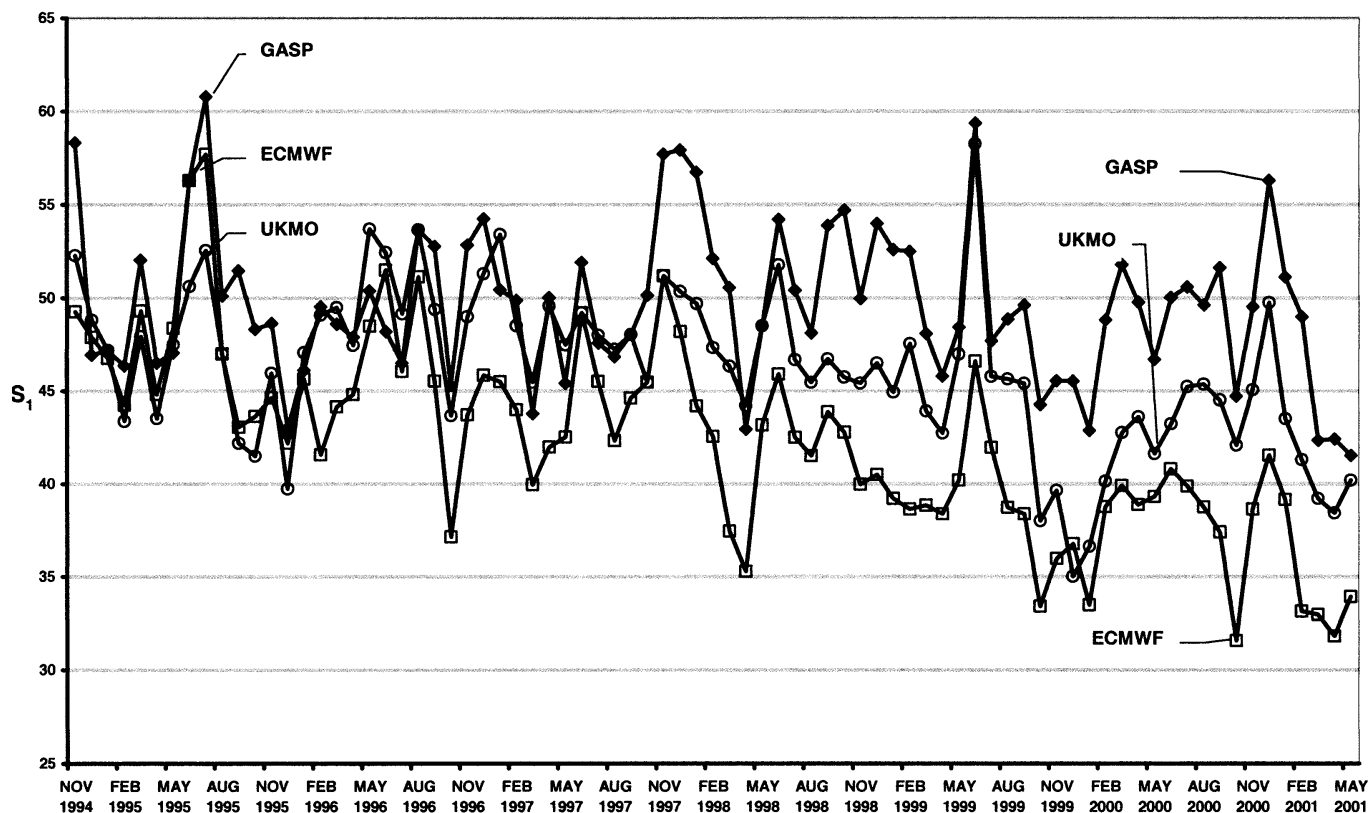

FIG. 9. Unsmoothed monthly $S_{1}$ skill scores of predictions of 500-hPa heights at $72 \mathrm{~h}$ by the ECMWF, UKMO, and GASP models, for the region south of and including $55^{\circ} \mathrm{S}$ for the period Nov 1994-May 2001 inclusive.

sphere exchanges are deficient as noted by, for example, Bromwich et al. (1999) — in the January 1999 case the lower model Antarctic atmosphere may be too warm. Having said this, it is intriguing that the maximum mean $500-\mathrm{hPa}$ errors occurred about the same areas where there were major analysis discrepancies among the models; compare, for example, Fig. 12 with Fig. 4a. If this was more than chance, then it suggests that perhaps the ECMWF analyses themselves are in question. In contrast to the mean error fields, Fig. 13 indicates that the ECMWF model's greatest rms errors occurred in January 1999 over the Southern Ocean west of South America, reflecting perhaps the great variability in synoptic systems moving through the area.

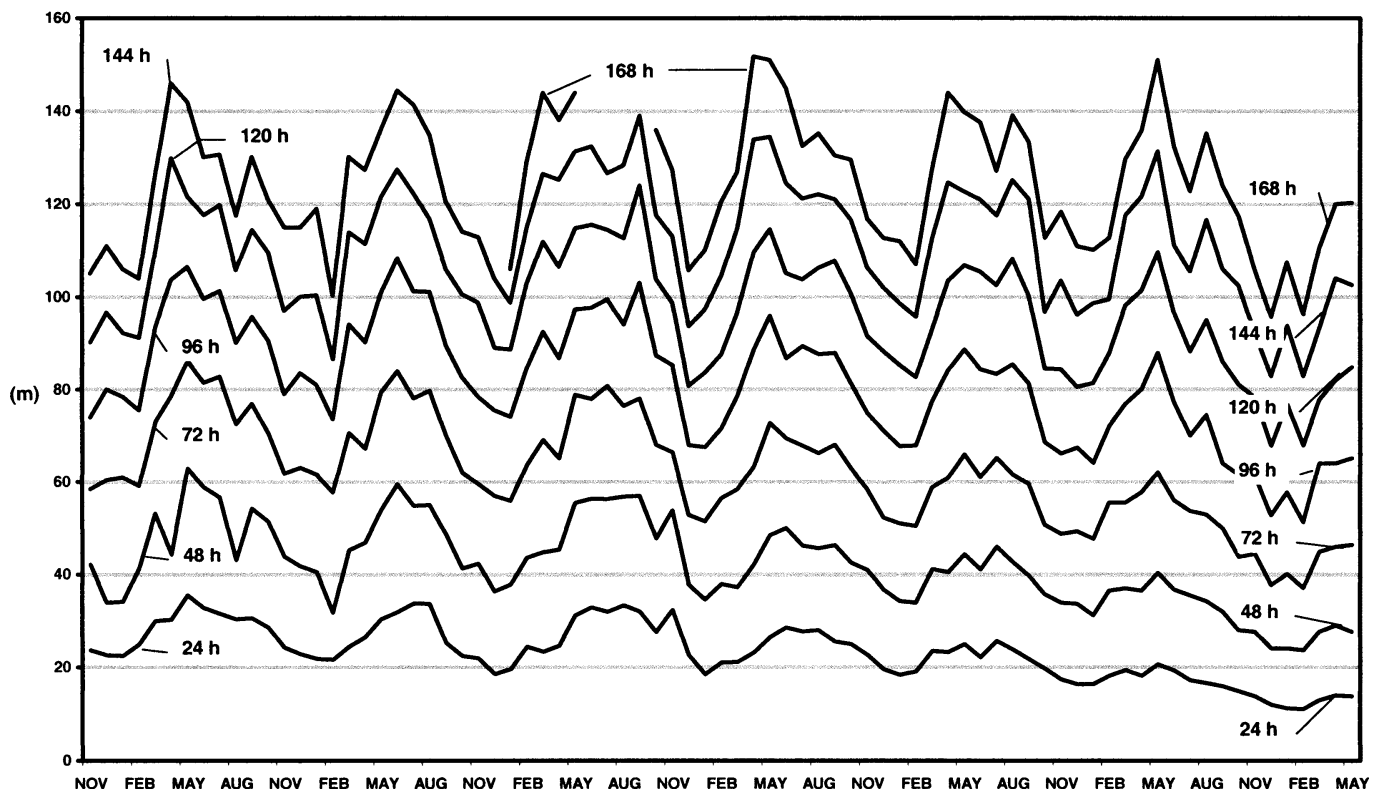

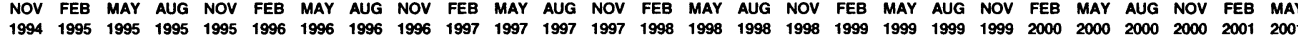

FIG. 10. Unsmoothed monthly rms errors in predictions of 500-hPa heights by the ECMWF model for the region south of and including $55^{\circ} \mathrm{S}$ for the period Nov 1994-May 2001 inclusive. (The 24-h forecast time is the bottom graph, with the 48-, 72-, 96-, 120-, 144-, and 168-h forecast time step graphs in sequence above the 24-h graph.) 
(a)

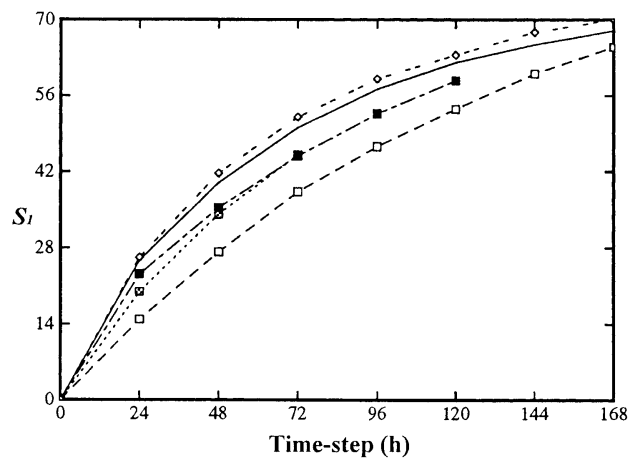

(c)

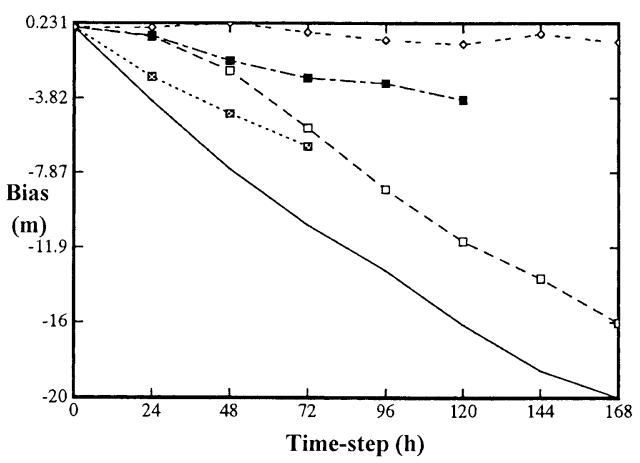

(b)

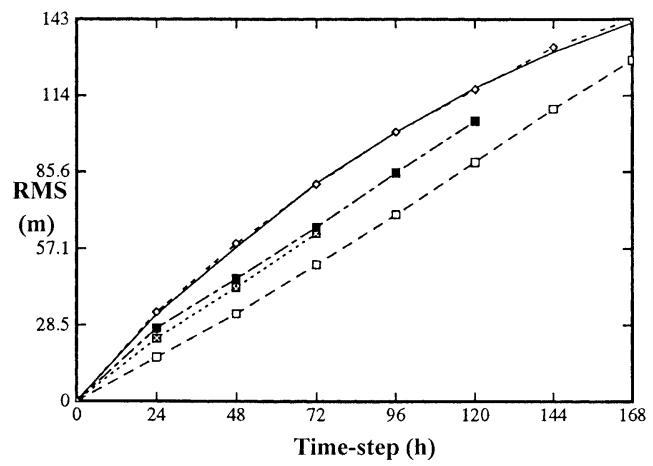

(d)

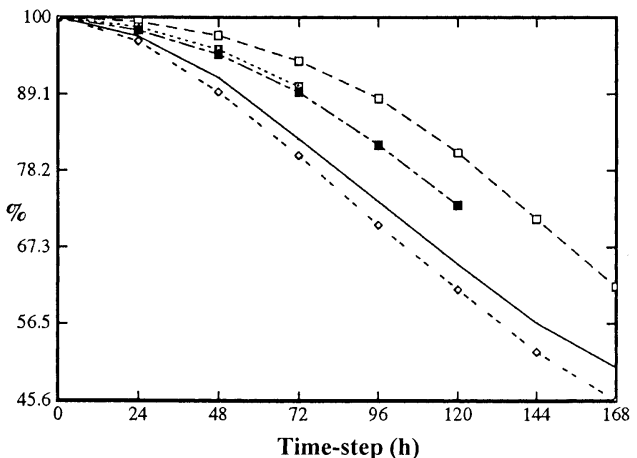

ㅁ- - - E ECMWF

UKMO

ש....... USAVN

GASP

$\diamond-\cdots-\infty$ MMA

FIG. 11. Statistics on the performance of some global model predictions of 500-hPa heights for the region south of and including $55^{\circ} \mathrm{S}$ for the period 1 Jul-30 Sep 2000: (a) $S_{1}$ skill score, (b) rms errors, (c) bias, and (d) anomaly correlation coefficient.

\section{d. GASP model performance with emphasis on moisture}

It was noted above that the GASP model analyses had difficulty in faithfully representing the amount of moisture in at least parts of the Antarctic atmosphere. It would appear that the same might be said of the GASP prognoses for the Antarctic. Figures 14 and 15 are, for example, upper cross-sectional dewpoint relative humidity observational and $+48 \mathrm{~h}$ model prognosis data for Casey station for the first 6 weeks of 2001. From these figures, and from other observation-model comparisons (not shown) it is very evident that, overall, the prognoses for the Antarctic are too humid. On the other hand, comparisons between Macquarie Island radiosonde data and the GASP model NWP output for that station suggest that the GASP model appears to capture the essence of the high-latitude marine environment moisture fields much better. For example, Table 4 is a comparison between the "observed" (as calculated) mean daily (from 2300 and 1100 UTC data) precipitable water values for the first 6 weeks of 2001 for Casey station and Macquarie Island, and the GASP model analyses and $+48 \mathrm{~h}$ model prognosis data for the same period for the model grid points that best represent these stations in the model topography. The data in Table 4 have been binned into the lower troposphere (below $5000 \mathrm{~m}$ ) and the upper troposphere [above $5000 \mathrm{~m}$ but below around $16000 \mathrm{~m} \mathrm{(100} \mathrm{hPa)].} \mathrm{It} \mathrm{may} \mathrm{be} \mathrm{seen} \mathrm{that}$ the GASP model moisture analyses for Casey for this period were, overall, very close to the observations, but with the upper levels too dry by around $9 \%$. It may be inferred that the prognosis cycle contributed to most of the error in the $+48 \mathrm{~h}$ model moisture prognoses: an average positive bias per model run of close to $50 \%$ for the $+48 \mathrm{~h}$ model prognoses in the Casey area. In contrast, Table 4 indicates that at Macquarie Island errors in the precipitable water forecasts are much lower in the $+48 \mathrm{~h}$ GASP model prognoses. The overmoistening of the moisture profile at Casey may be partly due to an error in the model, which led to a loss of sea ice during this period. This problem was only detected after the current analysis. However, the sea-ice extent and 
(a)

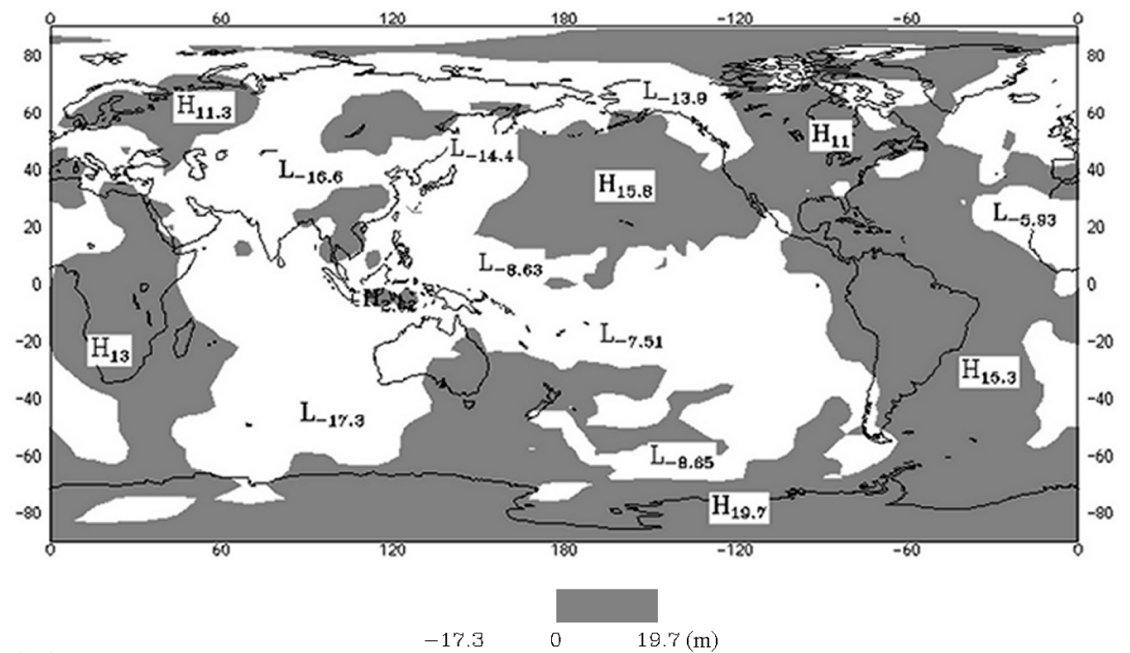

(b)

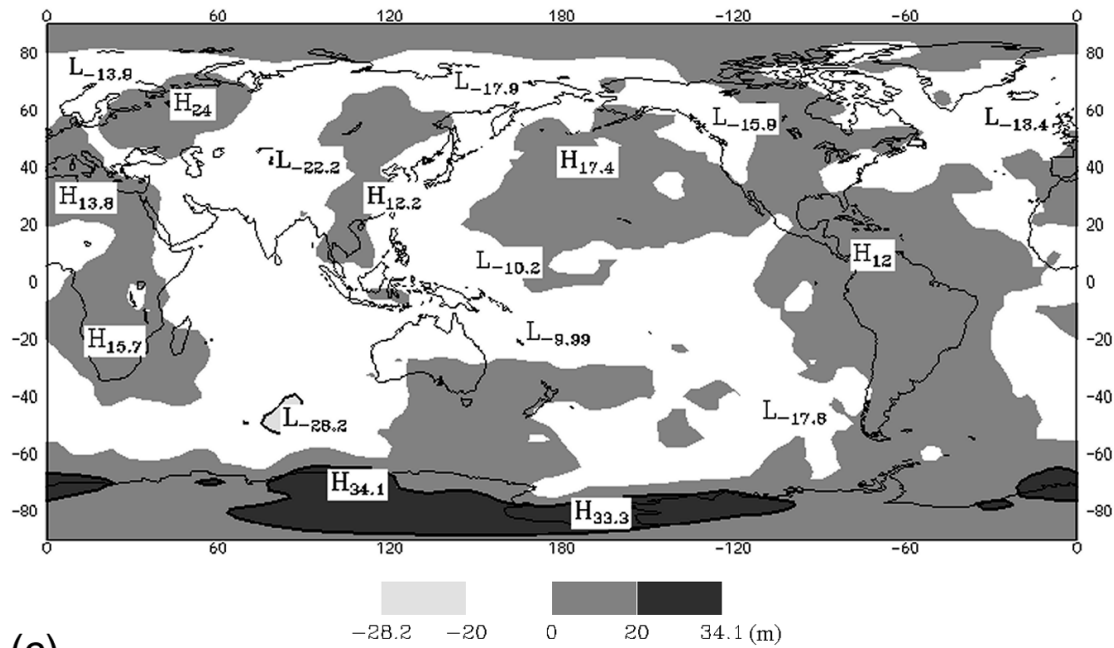

(c)

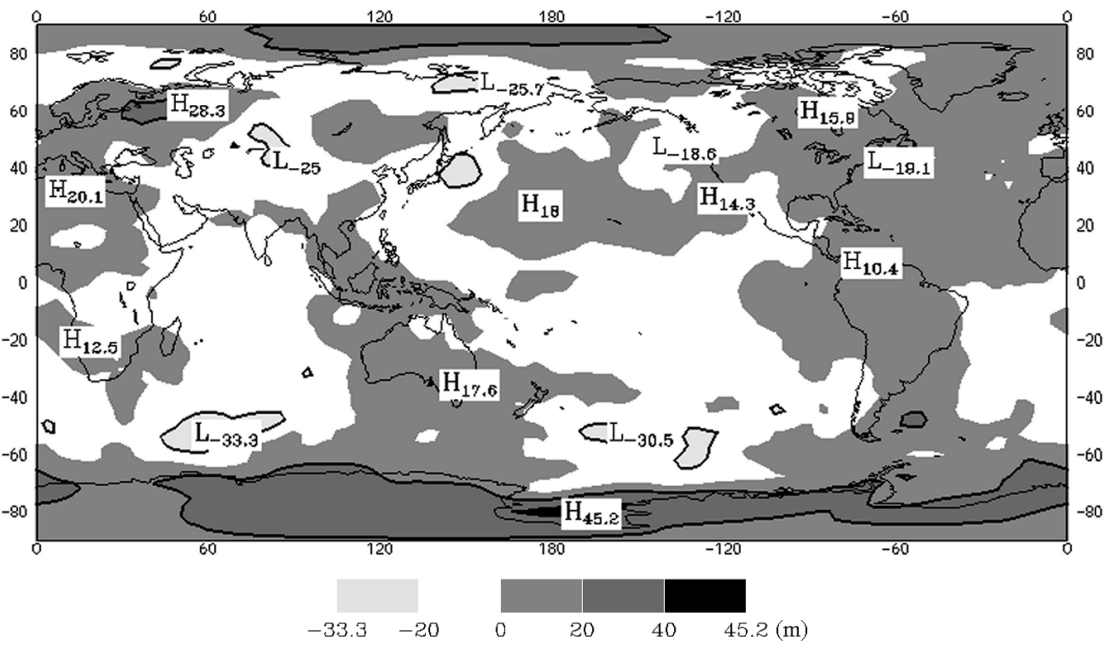

FIG. 12. Mean geopotential height errors (m) (prognosis minus analysis) for the ECMWF (a) +24 , (b) +48 , and (c) $+72 \mathrm{~h}$ prognoses valid at 1200 UTC for Jan 1999. 
(a)

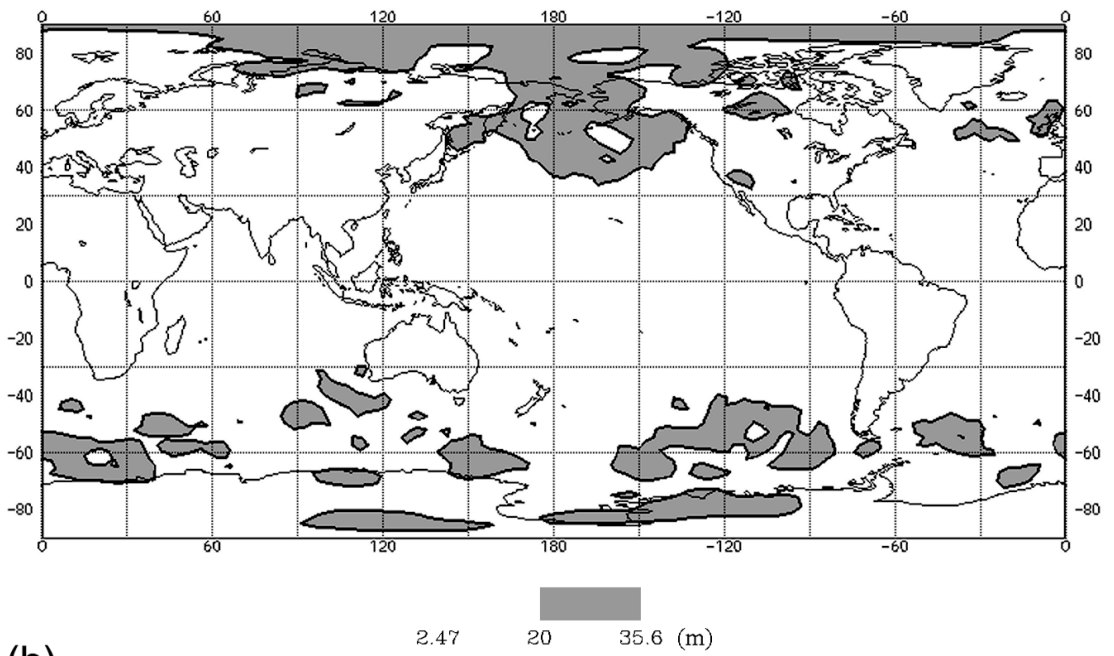

(b)

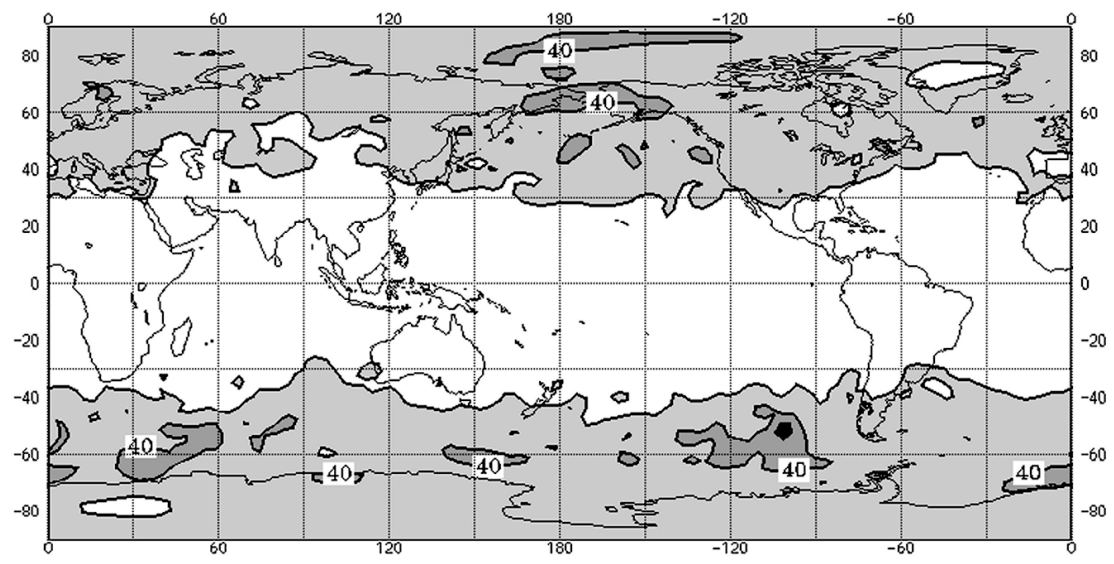

(c)
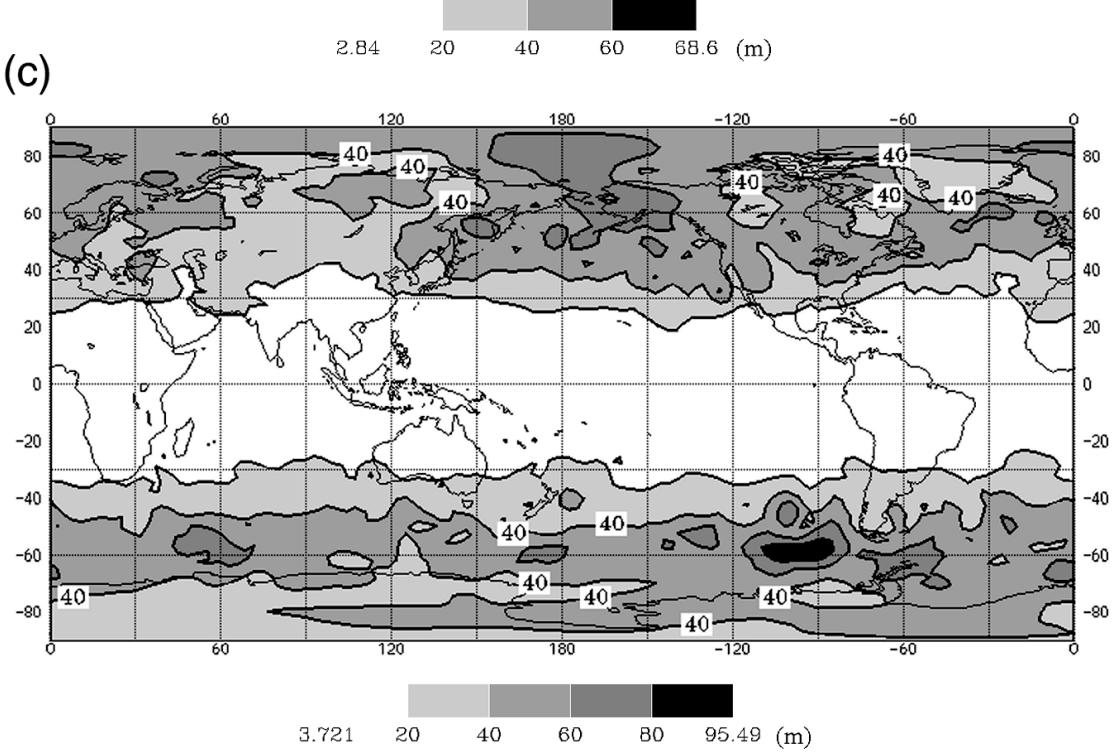

FIG. 13. Rms geopotential height errors (m) (prognosis minus analysis) for the ECMWF (a) +24 , (b) +48 , and (c) $+72 \mathrm{~h}$ prognoses valid at 1200 UTC for Jan 1999. 


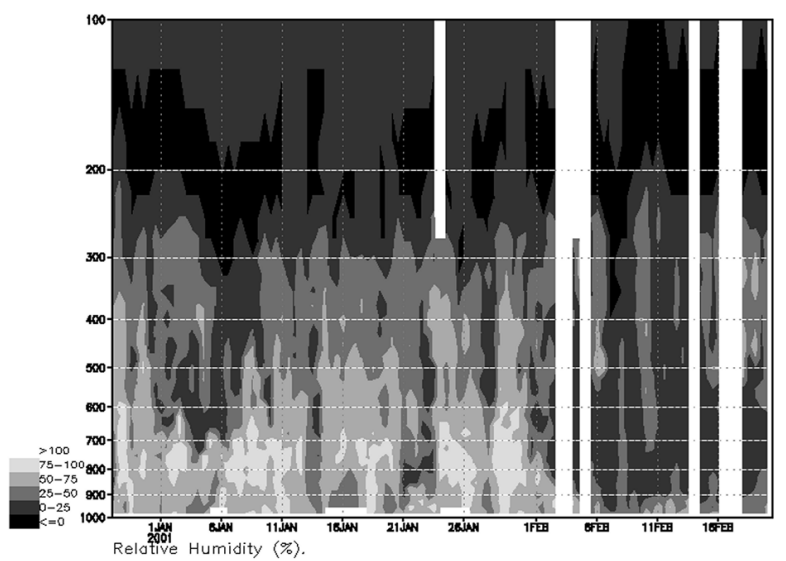

FIG. 14. Observed cross-sectional relative humidity data for Casey station for the approximate period 1 Jan-20 Feb 2001. [The left-hand scale is pressure $(\mathrm{hPa})$.]

thickness are at a minimum during this period of the year, often with large areas of open water close to Casey, and, moreover, the problem should not have affected the Macquarie Island results and so there does appear to be a tendency in GASP to overmoisten the troposphere during its prognosis cycle.

\section{An overview of uses and performance of NWP for weather forecasting in high southern latitudes from operational forecasters' perspectives}

Turner and Pendlebury (2000) is a handbook on forecasting for the Antarctic and had contributions from authors from many of the nations that operate in the Antarctic. This reference will be referred to here, for convenience, as the Antarctic Forecasting Handbook $(A F H B)$. The $A F H B$ indicates that the output of NWP systems is used as part of the preparation of most forecasts for the Antarctic including determination of the pressure field; assistance with surface wind forecasting; forecasts of the upper wind, temperature, and humidity;

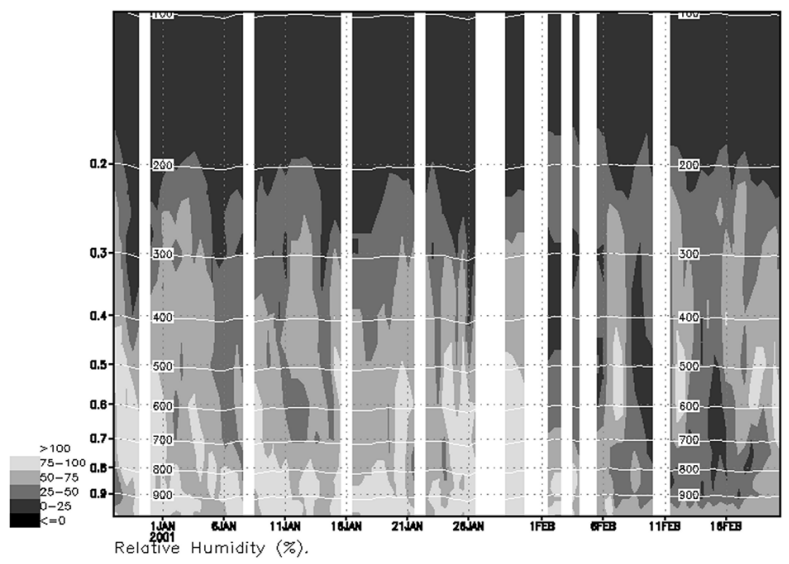

FIG. 15. GASP model $+48 \mathrm{~h}$ cross-sectional relative humidity predictions for Casey station for the approximate period 1 Jan-20 Feb 2001. [The left-hand scale is sigma level while the approximately horizontal lines are pressure (hPa).]

significant weather prognoses; cloud forecasting; precipitation forecasting; air-frame icing; jet stream turbulence forecasting; and sea wave and swell wave forecasting. NWP model output is particularly useful for the prediction of upper air parameters due to the data-sparse nature of the radiosonde network. Some specific inferences that can be made from the contributions to the $A F H B$ on the performance and utility of NWP output from global models in Antarctica are discussed below. It is recognized that the information presented is based on the subjective assessment and experience of operational forecasters. However, the authors see value in briefly drawing together this unique record of the views of the users of NWP output for an environment not usually considered by most researchers.

\section{a. Good performance of global NWP systems for synoptic-scale systems, particularly over the Southern Ocean}

There are many references in the $A F H B$ that attest to the overall useful performance of the global models with

TABle 4. Comparison of precipitable water estimates for Casey station and Macquarie Island averaged over all 2300 and 1100 UTC radiosonde ascents and coincident GASP model runs for the period 1 Jan 2001-20 Feb 2001, inclusive.

\begin{tabular}{|c|c|c|c|c|c|c|}
\hline \multirow[b]{2}{*}{$\begin{array}{l}\text { Analyses or } \\
\text { prognoses }\end{array}$} & \multicolumn{3}{|c|}{$\begin{array}{c}\text { Casey station precipitable } \\
\text { water }(\mathrm{mm})\end{array}$} & \multicolumn{3}{|c|}{$\begin{array}{l}\text { Macquarie Island } \\
\text { precipitable water } \\
(\mathrm{mm})\end{array}$} \\
\hline & $\begin{array}{l}\text { Column } \\
<5000 \mathrm{~m} \\
(\sim 510 \mathrm{hPa})\end{array}$ & $\begin{array}{l}\text { Column } \\
>5000 \mathrm{~m} \\
(\sim 510 \mathrm{hPa})\end{array}$ & $\begin{array}{c}\text { Total } \\
\text { column } \\
<\sim 15950 \mathrm{~m} \\
(100 \mathrm{hPa})\end{array}$ & $\begin{array}{l}\text { Column } \\
<5000 \mathrm{~m} \\
(\sim 530 \mathrm{hPa})\end{array}$ & $\begin{array}{l}\text { Column } \\
>5000 \mathrm{~m} \\
(\sim 530 \mathrm{hPa})\end{array}$ & $\begin{array}{c}\text { Total } \\
\text { column } \\
<\sim 16150 \mathrm{~m} \\
(100 \mathrm{hPa})\end{array}$ \\
\hline Observed & 4.68 & 0.34 & 5.02 & 11.16 & 0.82 & 11.98 \\
\hline GASP analyses & 4.65 & 0.31 & 4.96 & 11.18 & 0.94 & 12.12 \\
\hline Analyses deficit $(-)$ or surplus $(+)$ & $\begin{array}{l}-0.03 \\
(-1 \%)\end{array}$ & $\begin{array}{l}-0.03 \\
(-9 \%)\end{array}$ & $\begin{array}{l}-0.06 \\
(-1 \%)\end{array}$ & $\begin{array}{l}+0.02 \\
(+0 \%)\end{array}$ & $\begin{array}{c}+0.12 \\
(+15 \%)\end{array}$ & $\begin{array}{l}+0.14 \\
(+1 \%)\end{array}$ \\
\hline GASP $+48 \mathrm{~h}$ model prognoses & 6.93 & 0.51 & 7.44 & 12.66 & 0.83 & 13.49 \\
\hline Prognoses deficit $(-)$ or surplus $(+)$ & $\begin{array}{l}+2.25 \\
(+48 \%)\end{array}$ & $\begin{array}{l}+0.17 \\
(+50 \%)\end{array}$ & $\begin{array}{l}+2.42 \\
(+48 \%)\end{array}$ & $\begin{array}{l}+1.50 \\
(+13 \%)\end{array}$ & $\begin{array}{c}+0.01 \\
(+1.2 \%)\end{array}$ & $\begin{array}{l}+1.51 \\
(+13 \%)\end{array}$ \\
\hline
\end{tabular}


respect to synoptic-scale systems over high-latitude southern oceanic areas, and the immediate coastal areas. Some examples include the following.

- For the South Shetland Islands (including King George Island) (near $\left.62^{\circ} \mathrm{S}, 59^{\circ} \mathrm{W}\right)$, and for the Rothera $\left(67^{\circ} 34^{\prime} \mathrm{S}, 68^{\circ} 8^{\prime} \mathrm{W}\right)$, Halley $\left(75^{\circ} 35^{\prime} \mathrm{S}, 26^{\circ} 27^{\prime} \mathrm{W}\right)$, and Neumayer $\left(70^{\circ} 39^{\prime} \mathrm{S}, 8^{\circ} 15^{\prime} \mathrm{W}\right)$ stations the major NWP models are reported to be now quite successful at analyzing and predicting the locations and depths of large-scale depressions. In particular around King George Island the model analyses can be used with a fair degree of confidence because of the large number (Fig. 3a) of in situ observations and extensive satellite data over the ice-free ocean. Moreover, at Rothera station, during the preparation of the surface pressure analyses, the frontal positions and low centers are determined from satellite imagery, but due to the complete lack of synoptic data to the west a great reliance is placed on the UKMO model's analysis of the pressure field in that area.

- For Molodezhnaya station $\left(67^{\circ} 40^{\prime} \mathrm{S}, 45^{\circ} 50^{\prime} \mathrm{E}\right)$, the ECMWF model was used with some success. In particular the $A F H B$ records, "It has to be noted that global model predictions for the area of the Cosmonauts Sea and to its north, in the absence of significant orographic effects, yielded quite satisfactory results in respect of the development of large-scale cyclones and blocking ridges not only for 1-2 days, but also for an extended period. These forecasts were obviously taken into account by weather forecasters and sometimes provide the only basis for forecasting for the area.",

There may of course be systematic model biases. For the South African National Antarctic Expedition (SANAE) station $\left(71^{\circ} 40^{\prime} \mathrm{S}, 2^{\circ} 50^{\prime} \mathrm{W}\right)$ one of the contributors to the $A F H B$ conducted a detailed evaluation of the ECMWF prognostic surface pressure fields and gradient winds and compared these with observations made at SANAE during February and March 1998. A main outcome from these comparisons, together with observations made during other station-relief seasons was that with the passage of a deep low south of $65^{\circ} \mathrm{S}$, the ECMWF model underestimated the wind speed at the ice shelf by $20 \%-50 \%$ and under extreme conditions by close to $100 \%$. However, although the model did not display much skill in accurately forecasting the wind speeds during storms, it was useful for determining trends and provides valuable guidance regarding the onset and cessation of strong winds. The reasons for the model underestimating the speed were believed by the $A F H B$ contributor to be threefold. First, the model tended to place the center of the depressions too far north. Second, the model underestimated the intensity of the continental high and rather than concentrating the pressure gradient along the ice-sea interface, spread the gra- dient across the coastal zone. And third, it was considered possible that the katabatic wind (which had an easterly component) could have been superimposed on the synoptic flow, thereby further increasing the wind speed.

\section{b. On the coarseness of the horizontal spatial resolution of available data and of the global models}

A further cause of the poor model performance mentioned above may have been that the ECMWF model was unable to adequately represent the steep rise in orography just inland of SANAE station; a chain of mountains, with peaks as high as $2500 \mathrm{~m}$ passes within $100 \mathrm{~km}$ of the ice shelf. A lack of appropriate resolution of such orographic features may lead to nonsimulation by models of effects such as the "barrier wind" [in which a barrier, such as a mountain chain, blocks the incident flow causing an enhanced airflow parallel to the mountain chain (O'Connor and Bromwich 1988; O'Connor et al. 1994)]. Moreover, in some areas of the Antarctic, mesoscale cyclones are common (Turner and Row 1989; Turner et al. 1993; Turner and Thomas 1994) and a lack of high spatial resolution observational data inhibits adequate initialization of the models: while this is not a failing of the models per se, it does appear to limit their usefulness. Even so, the models can provide some guidance. At Rothera, for example, it was reported in the $A F H B$ that the UKMO model has often hinted at the areas where mesoscale lows may develop by producing locally increased thickness gradients poleward of the main polar front and small thermal troughs that at first appeared to be an almost random drawing of the thickness lines, particularly in the area around the southern peninsula. Experience has shown that these small thermal troughs should not be ignored as several mesoscale systems have developed in association with them.

However, perhaps the most common reservation by Antarctic forecasting practitioners regarding the global models is the perceived limitation due, prima facie, to the models' horizontal spatial resolutions. In most cases this limitation relates to the poor representation of orography. From Table 1 it may be seen that as actober 1999 the effective spatial resolutions of the global models ranged from approximately $60 \mathrm{~km}$ (ECMWF and UKMO) to about $157 \mathrm{~km}$ (AVN). While a 60-km gridpoint spacing may seem impressive on a global scale it is still not sufficient to resolve many orographical features of importance in the high southern latitude context.

The following examples of limitations due to model resolution may be inferred from the $A F H B$ :

- For the remote southern Atlantic Gough Island $\left[40^{\circ} 21^{\prime} \mathrm{S}, 9^{\circ} 53^{\prime} \mathrm{W}\right.$, approximately $3300 \mathrm{~km}$ north of the coast of West Antarctica (Fig. 2), $13 \mathrm{~km}$ long and, at most, $7 \mathrm{~km}$ wide], when the wind had a westerly 
component, the ECMWF and UKMO model derived winds were often too strong when applied to the east coast and should be used with caution; that is to say, the effects of the island were not well resolved by the models.

- For King George VI Sound [spanning approximately $69^{\circ}-73^{\circ} \mathrm{S}$, near $68^{\circ} \mathrm{W}$, between Alexander Island and the Antarctic Peninsula (Fig. 2)] the narrow sound is not well represented in the current generation of global NWP models so model output needs to be used with care. This is particularly so since the northern part of the sound lies between the high orography of the Antarctic Peninsula to the east and the mountains of Alexander Island west of the sound.

- For the Larsen Ice Shelf [centered on about $68^{\circ} \mathrm{S}$, $63^{\circ} \mathrm{W}$, eastern side of the Antarctic Peninsula (Fig. $2)$ ], and for Neumayer station, the $A F H B$ notes that the poor representation of the orography of the Antarctic Peninsula causes problems with forecasting at these stations. Even though the Antarctic Peninsula spans some $13^{\circ}$ of latitude in length, it is less than $2^{\circ}$ of latitude in width for much of that length, and importantly, the higher parts of the mountain range along the spine of the peninsula are mostly subgrid scale. In particular at Neumayer station it was noted that low pressure developments leeward of the Antarctic Peninsula were sometimes not predicted by the ECMWF model and there were difficulties with the prediction of lows moving against the spine of the Antarctic Peninsula: often the model produced speeds of movement of these lows that were too fast, with phase differences of more than $24 \mathrm{~h}$.

- For the Casey station area the $A F H B$ reports that the ECMWF, GASP, and AVN models' representation of the orography around Casey, and in particular Law Dome (the summit of which is located some $130 \mathrm{~km}$ east-southeast of the station), is not represented at all well. In these models Law Dome appears as, "little more than a ridge pushing slightly out into the ocean" whereas, in fact, Law Dome is an ice dome with a summit over $1300 \mathrm{~m}$ high and with an approximate plan radius of around $130 \mathrm{~km}$. This deficiency, together with the models' inabilities to resolve the very strong slopes in the near coastal terrain in the Casey area (see, e.g., Turner et al. 2001) places substantial doubt on surface wind forecasts in the Casey area. For example, the strength of southeasterly outflow at Casey was often forecast by the models to be too strong-quite often by as much as $100 \%$. On the other hand the models had difficulty in discerning those occasions when Casey experienced a northeasterly outflow from around Law Dome. It was reported that storm force easterly winds at Casey were also not well handled, with the models not reproducing the downslope accelerations experienced at Casey (Turner et al. 2001). However, it was reported that these model biases were fairly consistent and could be accounted for when interpreting the model data.

\section{Concluding remarks}

Initialization of NWP models, that is the analysis cycle, has been implicated in some deficiencies of model performance in the Antarctic. Over the ocean areas, around the Antarctic continent, the performance of most models is slightly poorer than in midlatitudes because of the lack of in situ data and the high reliance on satellite sounder data. However, in the interior of the continent the output of the models is of very limited operational use. This probably comes about because of the difficulties in representing the orography of the Antarctic in the models, the fact that satellite sounder data are not used at tropospheric levels, and the relatively small number of automatic weather station observations on the Global Telecommunications System. Studies such as Bromwich et al. (1999) indicate that problems with NWP over continental Antarctica are increasingly receiving attention.

Weather forecasters and climatologists should always be aware of the strengths and weaknesses of NWP model output in the Antarctic. Moreover, as models are developed and new parameterization schemes introduced the nature of the errors can change since the model developers tend to check the results of their changes more carefully in the extrapolar regions, although there are exceptions (e.g., Simmons and Jiaban 1991). Intrinsically, however, there appears to be no reason as to why NWP should not eventually be very successful in the Antarctic context: an improvement in 500-hPaheight field prediction has already been noted. Diagnostic numerical simulations (e.g., Parish 1984; Hines et al. 1995) appear to provide very useful and realistic information on the Antarctic atmosphere. Moreover, as the global models' grid resolutions improve one might expect that many hitherto poorly represented geographical features will find adequate representation in the models. In the meantime work proceeds on the application of mesoscale models for the Antarctic. For example, Cassano et al. (2000) describe the application of the polar version of the Pennsylvania State UniversityNational Center for Atmospheric Research fifth-generation Mesoscale Model (MM5) polar model to the 1999/ 2000 field season at McMurdo station $\left(77^{\circ} 52^{\prime} \mathrm{S}\right.$, $\left.166^{\circ} 40^{\prime} \mathrm{E}\right)$. Similarly, the Australian Bureau of Meteorology's Limited Area Prediction System (LAPS) model has been trialed at high latitudes around East Antarctica with a domain bounded by $0^{\circ}$ to $180^{\circ}$ and $80^{\circ}$ to $45^{\circ} \mathrm{S}$. Initial studies (Adams 2001) using the model in medium-resolution mode (25-km gridpoint resolution) indicate that the model is capturing some of the detail of weather in the circumpolar trough and broad-scale outflow off the Antarctic continent. Sensitivity studies are about to commence using the LAPS model on the effects of surface parameters such as sea surface temperatures, sea ice, large-scale polynyas, and albedo. Ultimately the model will be coupled with both a dynamic ocean model and sea-ice model. 
Acknowledgments. The authors are grateful to Mr. Jimmie Phang, of the Australian Bureau of Meteorology Research Centre's Medium Range Prediction Group, for producing the data shown in Figs. 4, 5, 12, and 13; and to Ms. Wilma Skinner of the Australian Bureau of Meteorology's National Meteorological and Oceanographic Centre, for producing data that allowed the preparation of Figs. 1, 9, 10, and 11.

\section{REFERENCES}

Adams, N., 1997: Model prediction performance over the Southern Ocean and coastal region around East Antarctica. Aust. Meteor. Mag., 46, 287-296.

_ 2001: Numerical weather prediction in East Antarctica. Preprints, Sixth Conf. on Polar Meteorology, San Diego, CA, Amer. Meteor. Soc., 331-334.

Baba, K., 1993: Relationship between positions of long wave upper air westerly troughs and weather conditions of geological survey area in the Antarctic Ocean. Polar Meteor. Glaciol., 45, 3-118

Bengtsson, L., 1991: Advances and prospects in numerical weather prediction. Quart. J. Roy. Meteor. Soc., 117, 855-902.

Bromwich, D. H., R. I. Cullather, and R. Grumbine, 1999: An assessment of the NCEP operational global spectral model forecasts and analyses for Antarctica during FROST. Wea. Forecasting, 14, 835-850.

_, A. N. Rogers, P. Kållberg, R. I. Cullather, J. W. C. White, and K. J. Kreutz, 2000: ECMWF analyses and reanalyses depiction of ENSO signal in Antarctic precipitation. J. Climate, 13, 14061420 .

Cassano, J. J., Li Lin, and D. H. Bromwich, 2000: BPRC mesoscale numerical weather prediction during the 1999/2000 Antarctic field season. Preprints, Antarctic Weather Forecasting Workshop, Columbus, $\mathrm{OH}$, Byrd Polar Research Center Miscellaneous Series M-419, 56-59.

Cullather, R. I., D. H. Bromwich, and R. W. Grumbine, 1997: Validation of operational numerical analyses in Antarctic latitudes. J. Geophys. Res., 102, 13 761-13 784

Fraedrich, K., and L. Leslie, 1991: Predictability studies of the Antarctic atmosphere. Aust. Meteor. Mag., 39, 1-9.

Hines, K. M., D. H. Bromwich, and T. R. Parish, 1995: A mesoscale modeling study of the atmospheric circulation of high southern latitudes. Mon. Wea. Rev., 123, 1146-1165.

- R. W. Grumbine, D. H. Bromwich, and R. I. Cullather, 1999: Surface energy budget of the NCEP MRF and NCEP-NCAR reanalysis in Antarctic latitudes during FROST. Wea. Forecasting, 14, 851-866.

Hollingsworth, A., K. Arpe, M. Tiedtke, M. Capaldo, and H. Savijarvi, 1980: The performance of a medium-range forecast mode in winter-Impact of physical parameterizations. Mon. Wea. Rev., 108, 1736-1773.

Hutchinson, H. A., S. Dixon, L. Marsh, L. H. Cowled, S. F. Pendlebury, H. R. Phillpot, M. J. Pook, and J. Turner, 1999: Reanalysis of weather data for Antarctica and the Southern Oceans during the FROST Project. Wea. Forecasting, 14, 909-919.

Kalnay, E., S. J. Lord, and R. D. McPherson, 1998: Maturity of operational numerical weather prediction: Medium range. Bull. Amer. Meteor. Soc., 79, 2753-2769.

Leonard, S., J. Turner, and S. Milton, 1997: An assessment of UK Meteorological Office numerical weather prediction analyses and forecasts for the Antarctic. Antarct. Sci., 9, 100-109.

O'Connor, W. P., and D. H. Bromwich, 1988: Surface airflow around Windless Bight, Ross Island, Antarctica. Quart. J. Roy. Meteor. Soc., 114, 917-938.

, D. H. Bromwich, and J. F. Carrasco, 1994: Cyclonically forced barrier winds along the Transantarctic Mountains near Ross Island. Mon. Wea. Rev., 122, 137-150.

Parish, T. R., 1984: Numerical study of strong katabatic winds over Antarctica. Mon. Wea. Rev., 112, 545-554.

Pendlebury, S., and G. Reader, 1993: Case study of numerical prediction of an extreme wind event in Antarctica. Preprints, Fourth Int. Conf. on Southern Hemisphere Meteorology and Oceanography, Hobart, Australia, Amer. Meteor. Soc., 124-125.

Phillpot, H. R., 1991: The derivation of 500-hPa height from automatic weather station surface observations in the Antarctic continental interior. Aust. Meteor. Mag., 39, 79-86.

_, 1997 : Some observationally-identified meteorological features of East Antarctica. Bureau of Meteorology Meteorological Study 42, $275 \mathrm{pp}$

Pook, M., and L. Cowled, 1999: On the detection of weather systems over the Antarctic interior in the FROST analyses. Wea. Forecasting, 14, 920-929.

Schwerdtfeger, W., 1984: Weather and Climate of the Antarctic. E1sevier, $261 \mathrm{pp}$.

Seaman, R. S., 1994: Monitoring a data assimilation system for the impact of observations. Aust. Meteor. Mag., 43, 41-48.

__ P. Steinle, W. Bourke, and T. Hart, 1993: The impact of manually derived Southern Hemisphere sea level pressure data upon forecasts from a global model. Wea. Forecasting, 8, 363-368.

— W. Wourke, P. Steinle, T. Hart, G. Embery, M. Naughton, and L. Rikus, 1995: Evolution of the Bureau of Meteorology's global assimilation and prediction system. Part 1: Analysis and initialisation. Aust. Meteor. Mag., 44, 1-18.

Simmons, A. J., and C. Jiabin, 1991: The calculation of geopotential and the pressure gradient in the ECMWF atmospheric model: Influence on the simulation of the polar atmosphere and on temperature analyses. Quart. J. Roy. Meteor. Soc., 117, 29-58.

Teweles, S., and H. B. Wobus, 1954: Verification of prognostic charts. Bull. Amer. Meteor. Soc., 35, 455-463.

Turner, J., and M. Row, 1989: Mesoscale vortices in the British Antarctic Territory. Polar and Arctic Lows, P. F. Twitchell, E. A. Rasmussen, and K. L. Davidson, Eds., Deepak, 347-356.

_ , and J. P. Thomas, 1994: Summer-season mesoscale cyclones in the Bellingshausen-Weddell region of the Antarctic and links with the synoptic-scale environment. Int. J. Climatol., 14, 871894.

Weather Forecasting Handbook. British Antarctic Survey, 700 pp. [Available from J. Turner, Physical Sciences Division, British Antarctic Survey, High Cross, Madingley Road, Cambridge CB3 OET, United Kingdom.]

, T. A. Lachlan-Cope, and J. P. Thomas, 1993: A comparison of Arctic and Antarctic mesoscale vortices. J. Geophys. Res., 98, 13 019-13034.

_ and Coauthors, 1996: The Antarctic First Regional Observing Study of the Troposphere (FROST) Project. Bull. Amer. Meteor. Soc., 77, 2007-2032.

—_, S. Pendlebury, L. Cowled, M. Jones, and P. Targett, 2000: Report on the First International Symposium on Operational Weather Forecasting in Antarctica. Bull. Amer. Meteor. Soc., 81, 75-94.

_- T. A. Lachlan-Cope, G. Marshall, S. Pendlebury, and N. Adams, 2001: An extreme wind event at Casey Station, Antarctica. $J$. Geophys. Res., 106, 7291-7311.

World Meteorological Organization, 2001: Results of the specific monitoring of the exchange of Antarctic meteorological data. WMO Letter 17.368/W/AN/T.9 to Permanent Representatives of WMO Member Countries Signatory to the Antarctic Treaty. [Available from H. Hutchinson, Chairman of the WMO Executive Council Working Group on Antarctic Meteorology, c/o GPO Box 727, Hobart, Tasmania 7001, Australia.] 